\title{
High throughput non-destructive assessment of quality and safety of packaged food products using phosphorescent oxygen sensors
}

\author{
Swagata Banerjee ${ }^{1, \text { }}$, Caroline Kelly ${ }^{1, \text { « }}$, Joseph P. Kerry ${ }^{2}$, Dmitri B. Papkovsky ${ }^{1 *}$ \\ ${ }^{1}$ School of Biochemistry and Cell Biology, University College Cork, Cavanagh Pharmacy \\ Building, College Road, Cork, Ireland \\ ${ }^{2}$ School of Nutrition and Food Science, University College Cork, Cavanagh Pharmacy \\ Building, College Road, Cork, Ireland
}

*Corresponding author: d.papkovsky@ucc.ie

These authors contributed equally to this work.

\begin{abstract}
Intelligent and active packaging technologies have gained attention in recent time due to increased demand by the consumers and manufacturers for sustaining the quality and safety of food products, improved shelf-life as well as real time monitoring of the packaging, storage and handling processes. In this context, phosphorescence based sensors for molecular oxygen $\left(\mathrm{O}_{2}\right)$ are important tools for monitoring of packaged products, new product development and optimisation. They allow fast, reversible, real-time and quantitative monitoring of residual $\mathrm{O}_{2}$ levels in a non-destructive manner, being superior over alternative systems. In this review, we describe the main types of phosphorescent $\mathrm{O}_{2}$-sensitive materials, fabrication methods and general requirements for sensors for food packaging applications. The main developments and representative examples are provided which illustrate the application of such sensors for monitoring of gaseous and dissolved $\mathrm{O}_{2}$ in various types of packaged foods and beverages. We also compare commercial $\mathrm{O}_{2}$ sensing instrumentation and disposable $\mathrm{O}_{2}$ sensors currently in use.
\end{abstract}

Keywords: Optical oxygen sensors; phosphorescence lifetime based oxygen sensing; disposable sensors; non-destructive analysis; food and beverage packaging, MAP foods, residual oxygen; high throughput analysis; food safety; quality assurance. 


\section{Introduction}

Applications of active and intelligent packaging technologies are gaining significant attention in recent time due to increased concern about the quality, sensory aspects, hygiene and safety of packaged food products, combined with increasing demands to improve the shelf-life of food products in a cost-effective manner, while minimising food waste and impact of packaging on the environment (Kerry, O'Grady, \& Hogan, 2006; Mohebi \& Marquez, 2015). Active packaging allows incorporation of additives, such as gas scavengers, $\mathrm{CO}_{2}$ emitters, ethanol emitters, temperature and moisture controllers, antimicrobial agents, to enhance the quality and sensory aspects of packaged foods (Ahvenainen, 2003; Han, 2003; Rooney, 1995; Suppakul, et al., 2003). Use of vacuum and particularly modified atmosphere packaging (MAP) systems is on a rise to store perishable foods in an oxygen free environment in order to maintain their quality and increase the shelf-life (Rooney, 1995). In MAP systems food products are enclosed in packs containing a mixture of natural gases $\left(\mathrm{N}_{2}\right.$, $\mathrm{CO}_{2}, \mathrm{O}_{2}$ ) in specific proportions, to retard the growth of microorganisms and other degradations processes (Yam, Yam, \& Davis, 2010). However, MAP processes themselves do not always guarantee the presence of right gas composition and require reliable control at the packaging site and verification throughout product lifespan. The residual oxygen levels in MAP products can increase due to factors such as gas permeability of the packaging material, gas trapping ability of enclosed food, compromised packaging, inefficient gas flushing, accidental damage during packaging, handling or transportation. Monitoring of MAP composition and particularly $\mathrm{O}_{2}$ levels in individual packs can therefore provide valuable information about the quality of food, integrity of packing material, efficiency of the packaging machine and process, storage conditions and handling.

Conventional headspace $\mathrm{O}_{2}$ analysis involves rather expensive analytical instruments like GC, electrochemical sensors (Clark-type $\mathrm{O}_{2}$ electrode)(Clark, et al., 1953), $\mathrm{O}_{2} / \mathrm{CO}_{2}$ gas analysers (e.g. Dansensor ${ }^{\mathrm{TM}}$ (Dansensor)), destructive sampling of the food package headspace and also requires skilled personnel. As well as providing limited sample throughput and creating wastage, these techniques only provide a time of analysis snapshot of the conditions in the selected packs, insufficient to detect all faulty packages and preform periodic rechecks. The operational efficiency of electrochemical $\mathrm{O}_{2}$ sensors is also influenced by gas flow rate, stirring rate, operational temperature, poisoning by other gases $\left(\mathrm{H}_{2} \mathrm{~S}\right)$ and fouling of membranes (Trettnak, et al., 1995).

Intelligent or 'smart' packaging approaches allow non-destructive monitoring of some properties of the enclosed food or the environment inside the pack and provide information about the current status of the food in such packs (Yam, Takhistov, \& Miltz, 2005). Various concepts of intelligent packaging currently exist that include indicators and sensors for different physical, chemical or biological variables which reflect the quality, safety of food products (Avella, et al., 2011; Borchert, Kerry, \& Papkovsky, 2013; Kuswandi, et al., 2011; Mills, 2005).

Indicators report presence or absence of a substance through a characteristic change, often the colour of the indicator material. Thus, package integrity is monitored through the incorporation of an optical indicator for $\mathrm{O}_{2}$, which consists of a redox dye, a strong reducing 
agent such as glucose and an alkaline compound to maintain alkaline $\mathrm{pH}$ and prevent rapid oxidation of the dye (Ahvenainen, Eilamo, \& Hurme, 1997; Krumhar \& Karel; Lawrie, Mills, \& Hazafy, 2013; Smolander, Hurme, \& Ahvenainen, 1997). The redox indicator can provide qualitative or semi-quantitative information about the $\mathrm{O}_{2}$ level through oxidation of the dye. Ageless Eye ${ }^{\mathrm{TM}}$, one of the commonly used indicators, produced by Mitsubishi Co to check integrity of food packages(AgelessEye), is based on the change in colour of methylene blue dye from colourless in the reduced form at $\left[\mathrm{O}_{2}\right] \leq 0.1 \%$ to blue oxidised form in the presence of $\mathrm{O}_{2}(\geq 0.5 \%)$. The indicator ink, represents irreversible $\mathrm{O}_{2}$ response (activated by UV light), can be printed on various surfaces. However, its high sensitivity often results in colour change at low $\mathrm{O}_{2}$ levels in MAP foods, giving false readouts.

Freshness indicators can inform about the quality and microbial contamination of the product through the colour change resulting from its interaction with the microbial metabolites (Smolander, 2008), such as the concentration of $\mathrm{H}_{2} \mathrm{~S}$ (Smolander, et al., 2002), volatile biogenic amines (Kaniou, et al., 2001; Loughran \& Diamond, 2000; Rokka, et al., 2004), ethanol (Randell, et al., 1995), lactic acid (Shu, Håkanson, \& Mattiasson, 1993). Timetemperature indicators (TTI) provide the temperature history of a food product over a period of time (Taoukis \& Labuza, 1989). TTIs can be based on temperature dependent diffusion $(3 \mathrm{~m})$, enzymatic (Vitsab) or polymerisation (Fresh-Check) reactions, and provide irreversible visual readout of the proper or improper temperature regime (but not the exact profile) to which the food product has been exposed to. Incorporation of radiofrequency identification (RFID) tags allows tracing and identification of faults (Kumari, et al., 2015). RFIDs can be combined with other indicators such as TTIs or sensors and provide real time information in a contact-less manner without being in the direct line-of-sight of a scanner.

Unlike the above indicator systems, optochemical sensors are composed of optically active materials which provide a reversible and quantitative response against specific parameter (Hugi \& Voirol, 2001; Kress-Rogers, 2001). Such sensors for various analytes have gained significant attention for their application in non-destructive monitoring quality of food such as freshness, deterioration due to heat or microbial spoilage, oxidative rancidity, compromised package integrity or barrier properties (Hugi \& Voirol, 2001; Kress-Rogers, 2001; Meng, et al., 2014). Residual $\mathrm{O}_{2}$ in packaged foods is one of the key markers of the quality of the product, the integrity of the packaging material and operation efficiency of the packaging lines. Elevated $\mathrm{O}_{2}$ levels can result in rapid deterioration of food-quality through lipid oxidation, destruction of citric acid leading to loss of flavour, fast ripening and browning through enzyme catalysed reactions, growth of microorganisms.

Photoluminescence (fluorescence/phosphorescence) based $\mathrm{O}_{2}$ sensors rely on the principle of quenching of luminescence intensity and lifetime of an oxygen-sensitive dye embedded in a polymeric matrix by sample $\mathrm{O}_{2}$. They offer several important advantages over the conventional systems including lack of oxygen consumption during measurement, reversible real-time operation, direct quantitative readout, contactless, non-destructive mode of detection, possibilities of miniaturization and up-scaling (Amao, 2003; Papkovsky \& Dmitriev, 2013; Wang \& Wolfbeis, 2014). Such low-cost, disposable, calibration-free solidstate $\mathrm{O}_{2}$ sensors can be applied on a large scale to detect package integrity, product 
deterioration, microbial growth and monitor quality and safety of food products along the packaging line.

In this review we focus on various applications of luminescent $\mathrm{O}_{2}$ sensors for quality control and safety assessment of packaged foods and beverages, describing corresponding sensor materials, measurement systems and some core food packaging applications.

\section{2. $\mathrm{O}_{2}$ Sensing by Photoluminescence Quenching}

$\mathrm{O}_{2}$ sensing using photoluminescent dyes rely on the collisional quenching of an electronically excited dye molecule by $\mathrm{O}_{2}$ molecules (Figure. 1A) (Lakowicz, 2006). The long-lived emission of phosphorescent dye molecules allows deactivation of their excited state through collisional interactions with $\mathrm{O}_{2}$ molecules, which decreases the emission intensity and lifetime in a concentration dependent manner. Ground state $\mathrm{O}_{2}$ molecules (paramagnetic; triplet configuration, ${ }^{3} \mathrm{O}_{2}$ ) can accept energy from the excited triplet state of the chromophore, thereby deactivating the chromophore and forming singlet oxygen $\left({ }^{1} \mathrm{O}_{2}\right)$. The short-lived ${ }^{1} \mathrm{O}_{2}$ usually reverts back to ground state $\mathrm{O}_{2}$; it can also react with surrounding chemical groups causing photo-oxidation.

\subsection{Detection Formats}

Luminescence spectroscopy allows quantitative monitoring of $\mathrm{O}_{2}$ concentrations through optical parameters of the sensors. The principal detection formats are measurement of the luminescence intensity (I) and luminescence lifetime $(\tau)$ of the $\mathrm{O}_{2}$ sensitive dye. The theoretical relationship between intensity/lifetime and the concentration of $\mathrm{O}_{2}$, in the case of purely collisional quenching, can be described by Stern-Volmer equation (eq. 1) (Lakowicz, 2006),

$$
\begin{gathered}
\frac{I_{0}}{I}=\frac{\tau_{0}}{\tau}=1+k_{q} \tau_{0}\left[O_{2}\right]=1+K_{S V}\left[O_{2}\right] \\
{\left[O_{2}\right]=\left(I_{0} / I-1\right) / K_{S V}} \\
\text { or }\left[O_{2}\right]=\left(\tau_{0} / \tau-1\right) / K_{S V}
\end{gathered}
$$

where $\mathrm{I}_{0}$ and $\mathrm{I}, \tau_{0}$ and $\tau$ are the luminescence intensities and lifetimes in the absence and in the presence of $\mathrm{O}_{2}$, respectively; $\mathrm{k}_{\mathrm{q}}$ is the bimolecular quenching rate constant, which gives a measure of the quenching efficiency or accessibility of the chromophore to $\mathrm{O}_{2} ; \mathrm{K}_{\mathrm{sv}}$ is the Stern-Volmer constant. Classical relationship between luminescent parameters and $\mathrm{O}_{2}$ concentration (i.e. calibration) and its linearization in Stern-Volmer plots are shown in Figure1B-C. However in practice and particularly for polymeric sensor materials, the SternVolmer plots deviate from the ideal linear nature depicted by equation 1, due to heterogeneous micro-environment of the dye and different $\mathrm{O}_{2}$ accessibilities. Under such conditions the dependence can be described by more complex (albeit less physically meaningful) models, such as "two-site model" (Carraway, et al., 1991; Demas, DeGraff, \& $\mathrm{Xu}$, 1995):

$$
\frac{I}{I o}=\frac{\tau}{\tau_{0}}=\frac{f}{1+K_{S V}^{1}\left[O_{2}\right]}+\frac{(1-f)}{1+K_{S V}^{2}\left[O_{2}\right]}
$$

where $f$ represents the fraction of the first emitting component, $\mathrm{K}_{\mathrm{SV}}^{1}$ and $\mathrm{K}_{\text {SV }}^{2}$ are the SternVolmer constants corresponding to each component. Originally developed for intensity 
quenching, Eqn. 3 is also applicable for lifetime based $\mathrm{O}_{2}$ sensing (Banerjee, Kuznetsova, \& Papkovsky, 2015; Borisov, et al., 2014).

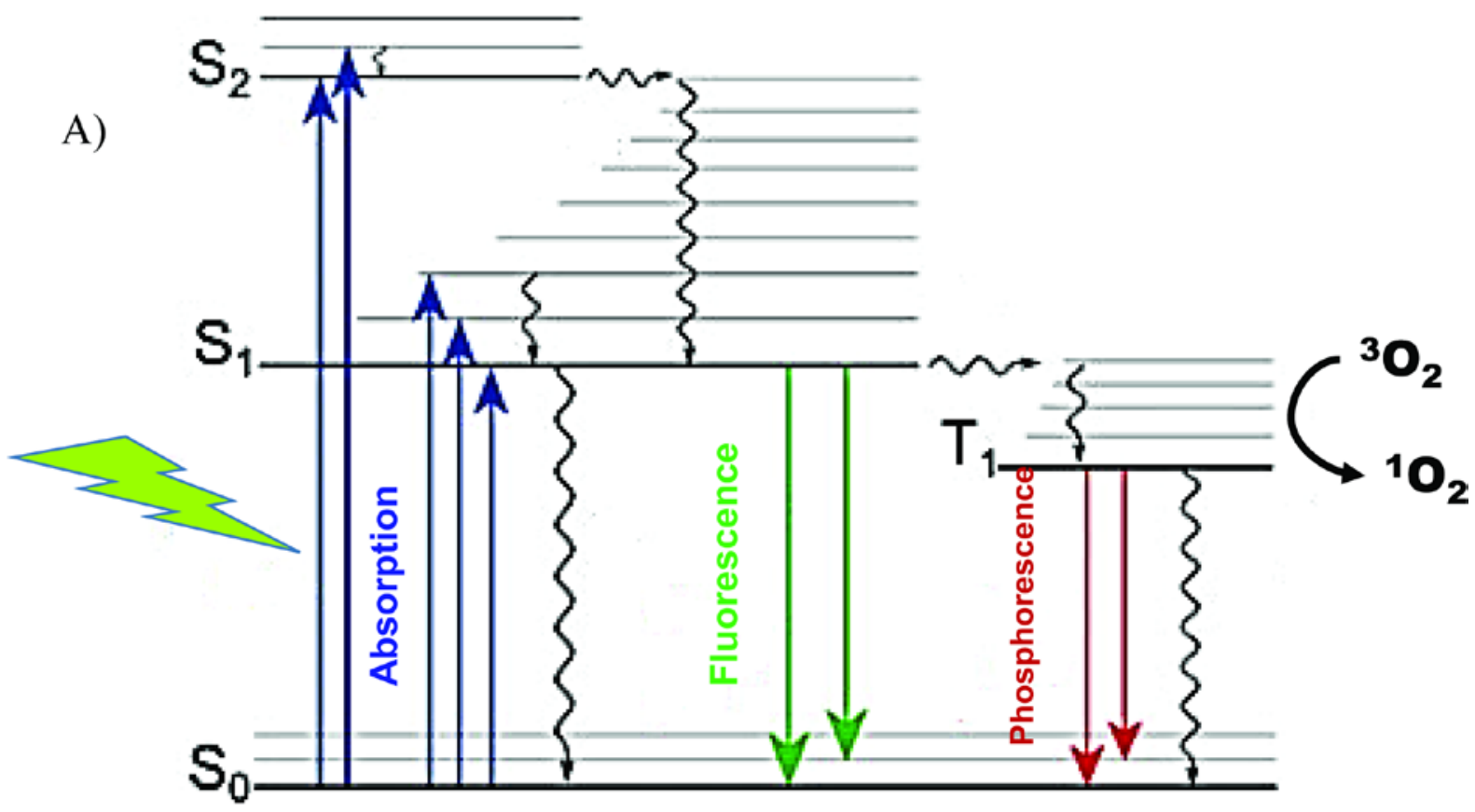

B)

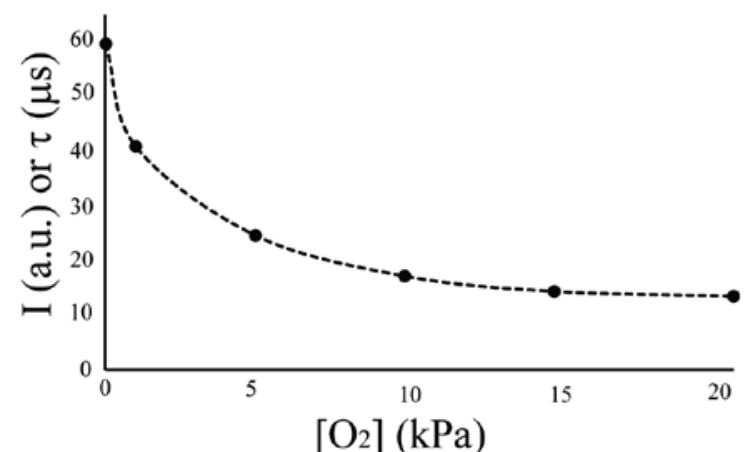

C)

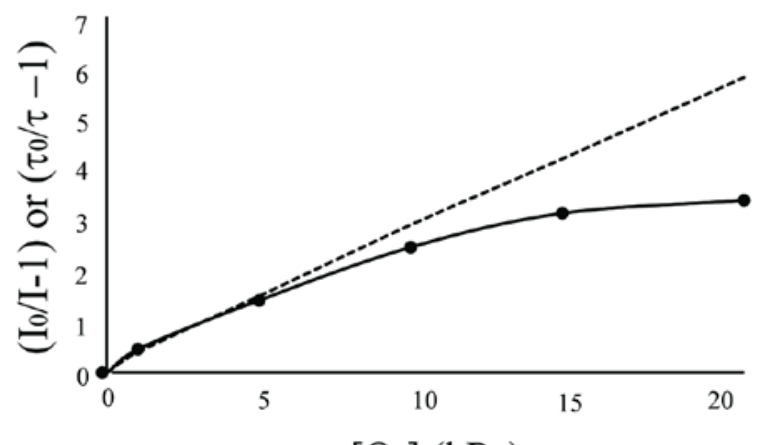

$\left[\mathrm{O}_{2}\right](\mathrm{kPa})$

Figure 1. Schematic representation of phosphorescence process and its quenching by $\mathrm{O}_{2}(\mathrm{~A})$, dependence of luminescence signal from the sensor (intensity, $I$ or lifetime, $\tau$ ) on $\mathrm{O}_{2}$ concentration (B) and its linearisation in Stern-Volmer plots showing the ideal (dotted line) and the more common curved (solid line) cases $(C)$.

Although intensity measurements have been used in some $\mathrm{O}_{2}$ sensors, this parameter can often be influenced by factors such as positioning of sample, fluctuation in light source, changes in optical path, detector drift, degradation or leaching of dyes. This results in large measurement errors, sensor-to-sensor and batch-to-batch variation, unstable calibration, the need of frequent re-calibrations. A modification of intensity measurements is the ratiometric mode, which measures intensities at two different wavelengths, one of which is sensitive to $\mathrm{O}_{2}$ and the other is not (the reference dye) (Kondrashina, et al., 2012; Koo Lee, et al., 2010; Napp, et al., 2011; Wang, et al., 2011; Xu, et al., 2001). The intensity ratio gives more stable readout and calibration, however sensor chemistry is more complex and factors such as 
detector noise, different extent of photo bleaching of the dyes, scattering and autofluorescence can still influence this parameter and affect the accuracy of measurements.

The emission lifetime on the other hand is an intrinsic parameter of a luminescent sensor material. It provides more stable calibration, independence on excitation intensity, detector sensitivity, measurement geometry and concentration of the reporter dye (though self-quenching of the dye at high concentrations can affect lifetime signals). For these reasons, the majority of modern sensors use luminescence lifetime-based detection of $\mathrm{O}_{2}$. Lifetime based $\mathrm{O}_{2}$ sensing can be realised either in time domain by tracing the luminescence decay after short-pulse excitation, or in frequency domain by measuring phase shift of the luminescent intensity signal under periodically modulated excitation.

\section{2. $\mathrm{O}_{2}$-Sensitive Dyes}

Luminescent $\mathrm{O}_{2}$ sensors are derived by encapsulating an $\mathrm{O}_{2}$-sensitive dye in a suitable $\mathrm{O}_{2}$-permeable matrix such as organic polymer or inorganic sol-gel (Amao, 2003; Papkovsky \& Dmitriev, 2013; Quaranta, Borisov, \& Klimant, 2012; Wang \& Wolfbeis, 2014). Commonly used luminescent dyes include complexes of transition metals and $\mathrm{Pt}(\mathrm{II})$ porphyrins (Amao, 2003; Amao \& Okura, 2009), which exhibit relatively long-lived emission at room temperature ( $\tau_{\mathrm{o}}$ in the $\mu$ s range) quenched by $\mathrm{O}_{2}$ in a concentration dependent manner (see Table 1).

$\left[\mathrm{Ru}(\mathrm{bpy})_{3}\right]^{2+}$ (where bpy $=2,2^{\prime}$-bipyridine), represents an early example of $\mathrm{Ru}(\mathrm{II})$ based dye used for sensor fabrication (Cook, et al., 1984; Lippitsch, et al., 1988; Mills, Graham, \& O'Rourke, 2014; Wang \& Wolfbeis, 2014; Wolfbeis, Leiner, \& Posch, 1986). It was later replaced by $\left[\mathrm{Ru}(\mathrm{dpp})_{3}\right]^{2+}$ dye series, where dpp stands for tris(4,7-diphenyl-1,10phenanthroline). $\left[\mathrm{Ru}(\mathrm{dpp})_{3}\right]^{2+}$ dyes display moderately intense absorption and a broad MLCT emission in the visible region with an unquenched lifetime $\tau_{\mathrm{o}}$ of $\sim 6.4 \mu \mathrm{s}$ and quantum yield $\phi$ of $\sim 0.3$ (Table 1) (Alford, et al., 1985). $\left[\mathrm{Ru}(\mathrm{dpp})_{3}\right]^{2+}$ has been studied in various $\mathrm{O}_{2}$-sensitive matrices including sol-gel (MacCraith, et al., 1993; Xu, et al., 2001), organically modified silicate (ormosil) (Badocco, Mondin, \& Pastore, 2012; Chen, et al., 2002; Klimant, et al., 1999; McDonagh, et al., 2001; Tang, et al., 2003), organic polymers such as polystyrene (PS)(Hartmann, Leiner, \& Lippitsch, 1995; Klimant, et al., 1997), polysulfone (PSu) (Badocco \& Pastore, 2008), ethyl cellulose (EC) (Draxler, et al., 1995), polydimethyl silloxane (PDMS) (Xu, et al., 1994). Ionic complexes such as $\left[\mathrm{Ru}(\mathrm{dpp})_{3}\right]^{2+}$ suffer from poor solubility in hydrophobic polymers. To overcome this, such dyes can be adsorbed on $\mathrm{SiO}_{2}$ or $\mathrm{TiO}_{2}$ particles and then incorporated into hydrophobic polymeric binder (Mills \& Graham, 2013; Wolfbeis, et al., 1986), or they can be ion-paired with lipophilic anions such as dodecyl sulphate, trimethylsilylpropanesulfonate, tetraphenyl borate (Klimant \& Wolfbeis, 1995; Mills \& Thomas, 1997). Thus, $\mathrm{O}_{2} \mathrm{xyDot}^{\mathrm{TM}}$ sensor produced by Oxysense uses $\left[\mathrm{Ru}(\mathrm{dpp})_{3}\right]\left(\mathrm{ClO}_{4}\right)_{2}$ incorporated in silicone rubber. $\mathrm{Ru}(\mathrm{II})$ dyes are excitable with blue LEDs (Oxysense), but their disadvantages are moderate brightness, relatively short lifetimes and excitation wavelengths, high temperature sensitivity of the triplet state (Alford, et al., 1985; Forster, 2002).

Pt(II)-porphyrins (Amao \& Okura, 2009) display strong absorption in the UV region ( $\lambda_{\max } \sim 390-420 \mathrm{~nm}$ - Soret band), weaker absorption Q bands in the visible region, strong 
room temperature phosphorescence with large Stokes shift and emission lifetime around 50$100 \mu$ s strongly quenched by $\mathrm{O}_{2}$. $\mathrm{Pd}(\mathrm{II})$-porphyrins display 5-10 times longer lifetime and correspondingly higher sensitivity towards $\mathrm{O}_{2}$ compared to their Pt(II) analogues (Eastwood $\&$ Gouterman, 1970). Such dyes are useful for trace $\mathrm{O}_{2}$ analysis, while at ambient $\mathrm{O}_{2}$ levels $(\sim 15-25 \mathrm{kPa})$ they are strongly quenched producing week phosphorescent signals and poor resolution in $\mathrm{O}_{2}$ measurements.

$\mathrm{Pt}(\mathrm{II})$-octaethylpophyrin was initially used in $\mathrm{O}_{2}$ sensing (Amao, et al., 2002; Douglas \& Eaton, 2002; Lee \& Okura, 1997a; Papkovsky, 1995; Papkovsky, et al., 1992), but it has modest photostability and undergoes rapid photobleaching in polymeric matrices(Puklin, et al., 2000). In Pt(II)-tetrakis-(pentafuorophenyl)porphyrin (PtTFPP) dye contain the electronwithdrawing perfluorinated substituents which lower its oxidation potential and improve photostability (Amao, Miyashita, \& Okura, 2001; Lee \& Okura, 1997b; Puklin, et al., 2000). This dye has been extensively used in various polymers including PS (Amao, et al., 2001; Lee \& Okura, 1997b), PSu (Badocco, et al., 2012; Xue, et al., 2015), sol-gel matrices (Chu \& Chuang, 2015; Chu \& Lin, 2014; Chu \& Lo, 2011) and co-polymers. $\mathrm{O}_{2}$ sensors have been developed by covalently linking PtTFPP to poly(2-hydroxyethyl methacrylate)-copolyacrylamide (Tian, Shumway, \& Meldrum, 2010), co-polymers of styrene and pentafluorostyrene (Koren, Borisov, \& Klimant, 2012), polyfluorene co-polymer (Dmitriev, et al., 2015). Such sensor materials overcome the problems of migration and leaching of dye from polymeric matrix, while retaining the $\mathrm{O}_{2}$ sensitivity and photostability. One major limitation with PtTFPP is that high brightness can only be achieved upon excitation at $\sim 400$ $\mathrm{nm}$ (Soret band), while under visible light excitation (Q-bands 500-520 nm) it has moderate brightness and therefore less favourable for $\mathrm{O}_{2}$ sensing.

Dyes absorbing in the red region and emitting in the far-red/NIR region are preferred over the UV and visible light excitable dyes, due to minimal interference from sample autofluorescence, background from support media and reduced effects of excitation on lightsensitive products. Compared to the parent porphyrins, $\mathrm{Pt}(\mathrm{II})$ complexes of pophyrin-ketones (Papkovsky, et al., 1995) and pophyrin-lactones (Khalil, et al., 2002), synthesised by oxidation of the porphyrin ring, display red-shifted Q-bands and enhanced absorption. The PtOEPK displays phosphorescence around $759 \mathrm{~nm}$ with unquenched lifetime of $\sim 61 \mu \mathrm{s}$ in polystyrene (Papkovsky, et al., 1995), excitable with bright and low-cost yellow LEDs. While studied in several different polymers (Klimant, et al., 1997; Kolle, et al., 1997) and used extensively in packaging applications (see Section 3 below), PtOEPK dye has relatively low emission yield (resulting in moderate brightness of sensors) and high cost.

Porphyrins with extended $\pi$-conjugation such as tetrabenzoporphyrins (TBPs), tetranaphtho[2,3]porphyrins (TNPs) also exhibit red absorption and bright emission (Rogers, et al., 2003; Vinogradov \& Wilson, 1997; Vinogradov \& Wilson, 1995). Thus, the Pt(II)tetraphenyltetrabenzoporphyrin (PtTPTBP) in toluene has a strong absorption at $\mathrm{Q}$ band at $614 \mathrm{~nm}\left(\varepsilon=13.6 \times 10^{4} \mathrm{M}^{-1} \mathrm{~cm}^{-1}\right)$ and strong phosphorescence with $\lambda_{\max }=770 \mathrm{~nm}$ and quantum yield $\sim 0.5$ (Borisov S. M., et al., 2009). The bright, photostable and longwave PtTBP dyes have been used to produce robust optical sensors, including those with $\mathrm{O}_{2}$ reporter dye covalently conjugated to silicone (Müller, et al., 2015). They are excitable with orangered LEDs. 
Several other dyes including cyclometalated iridium (Borisov \& Klimant, 2009; Borisov \& Klimant, 2007; Köse, et al., 2005; Li, et al., 2015), lanthanide (Borisov \& Klimant, 2012; Borisov, et al., 2014; Law, et al., 2009; Songzhu, et al., 2010) and other metal complexes (Medina-Rodriguez, et al., 2015) have also been described for $\mathrm{O}_{2}$ sensing. Noble or rare metal free organic chromophores such as, camphorquinone (Charlesworth, 1994), erythrosine B (Gillanders, et al., 2004; Lam, Chan, \& Lo, 2001), BODIPY derivatives (Banerjee, et al., 2015; Ermolina, et al., 2014) also exhibit phosphorescence at room temperature effectively quenched by $\mathrm{O}_{2}$, but these dyes are associated with lower wavelength excitation, low brightness, considerable photodecomposition. For more details see the recent reviews (Amao, 2003; Quaranta, et al., 2012; Wang \& Wolfbeis, 2014).

Table 1. Summary of photophysical properties of the commonly used $\mathrm{O}_{2}$-sensitive dyes

\begin{tabular}{|c|c|c|c|c|c|c|}
\hline Dye & $\begin{array}{l}\lambda_{\max }{ }^{\mathrm{Abs}} / \mathbf{n m} \\
\left./ \mathbf{M}^{-1} \mathbf{c m}^{-1}\right)\end{array}$ & $\begin{array}{l}\lambda_{\max } \mathrm{Em} \\
/ \mathbf{n m} \\
\end{array}$ & $\phi^{\mathrm{a}}$ & $\tau(\mu s)^{a}$ & $\begin{array}{l}\text { Brightness } \\
\text { in } \text { PS }^{\mathbf{b}}\end{array}$ & Ref. \\
\hline & $\begin{array}{l}463 \\
\left(2.86 \times 10^{4}\right)\end{array}$ & 618 & 0.366 & 6.4 & 10467 & $\begin{array}{l}\text { (Alford, } \\
\text { et al., } \\
\text { 1985) }\end{array}$ \\
\hline \multicolumn{7}{|l|}{$\left[\operatorname{Ru}(\mathrm{dpp})_{3}\right]^{2+}$} \\
\hline & \begin{tabular}{|l}
394 \\
$\left(32.3 \times 10^{4}\right)$ \\
504 \\
$\left(2.32 \times 10^{4}\right)$ \\
538 \\
$\left(2.94 \times 10^{4}\right)$
\end{tabular} & $\begin{array}{l}647 \\
710 \\
\text { (shoulde } \\
\text { r) }\end{array}$ & 0.088 & 60 & $\begin{array}{l}92000 \\
5600 \\
7600\end{array}$ & $\begin{array}{l}\text { (Lai, et } \\
\text { al., 2004) } \\
\text { (Borisov, } \\
\text { Nuss, \& } \\
\text { Klimant, } \\
\text { 2008) }\end{array}$ \\
\hline \multicolumn{7}{|l|}{ PtTFPP } \\
\hline & $\begin{array}{l}398 \\
\left(8.62 \times 10^{4}\right) \\
592 \\
\left(5.51 \times 10^{4}\right)\end{array}$ & 758 & $0.12^{\mathrm{c}}$ & $60^{\mathrm{c}}$ & $\begin{array}{l}19000 \\
12000\end{array}$ & $\begin{array}{l}\text { (Papkovs } \\
\text { ky, et al., } \\
1995 \text { ) }\end{array}$ \\
\hline Pt-OEPK & & & & & & \\
\hline
\end{tabular}




\begin{tabular}{|c|c|c|c|c|c|c|}
\hline & $\begin{array}{l}430 \\
\left.\left(21.2 \times 10^{4}\right)\right) \text {, } \\
615 \\
\left.\left(14.6 \times 10^{4}\right)\right)\end{array}$ & 773 & 0.60 & 50 & $\begin{array}{l}149000 \\
102000\end{array}$ & $\begin{array}{l}\text { (Borisov } \\
\text { S. M., et } \\
\text { al., 2009) }\end{array}$ \\
\hline РtТРТВРF & & & & & & \\
\hline
\end{tabular}

${ }^{\mathrm{a}}$ Quantum yield, $\Phi$ and lifetime $\tau$ values refer to $\mathrm{O}_{2}$-free solution. ${ }^{\mathrm{b}}$ For brightness, values were taken from Ref (Borisov, et al., 2008), calculated using, $\phi$ of $\operatorname{Ir}(\mathrm{Cs})_{2}$ (acac) in PS as 1; ${ }^{c}$ in micellar sulphite solution

\subsection{Polymeric Host}

In a sensor, an $\mathrm{O}_{2}$-sensitive dye is encapsulated in a polymeric host, which provides it the desired quenching by $\mathrm{O}_{2}$ and additional shielding from other quenchers in the surrounding medium/test sample. The polymer is usually chosen such that it has good compatibility and solubility for the dye, optimal quenching by $\mathrm{O}_{2}$ and eliminates dye aggregation and leaching (Korotcenkov, 2014). The polymer should possess high chemical, mechanical and thermal stability and not change its microstructure over time. The permeability of $\mathrm{O}_{2}$ through the polymer and the lifetime of the dye determine the sensitivity of the sensor. Dyes with short emission lifetime such as $\left[\mathrm{Ru}(\mathrm{dpp})_{3}\right]^{2+}$ require polymers with high $\mathrm{O}_{2}$ permeability, such as silicones and fluorinated copolymers. Pt-porphyrins having longer lifetimes are compatible with a broader range of plastics including PS, PSu, food-grade polymers polyethylene (PE) and polypropylene (PP), special and biodegradable polymers such as polylactic acid (PLA) and polyphenylidene sulphide (PPS).

PS, PSu and silicones are commonly used in $\mathrm{O}_{2}$ sensors, due to their moderate to high gas permeability, high chemical and mechanical stability, and ability to form transparent coatings (Wang \& Wolfbeis, 2014). Alternatively dyes can be adsorbed on $\mathrm{SiO}_{2}$ or $\mathrm{TiO}_{2}$ beads and then incorporated in the polymer (Mills \& Graham, 2013; Wolfbeis, et al., 1986), but such sensor materials tend to be more heterogeneous. To achieve fast response to $\mathrm{O} 2$, sensor materials are usually prepared as thin film coatings. For easier handling and improved mechanical stability sensor coatings are applied on solid support material such as tip of optical fibre, glass slide, or more commonly on polyester film (Mylar ${ }^{\circledR}$ ) (Klimant \& Wolfbeis, 1995; Moreno-Bondi, et al., 1990) or microporous membranes (Papkovsky, O'Riordan, \& Guilbault, 1999; Papkovsky, et al., 1998). The latter facilitate production of uniform coatings, enhance phosphorescent signals, prevent delamination of sensor material, facilitate handling, and still retain fast response to $\mathrm{O}_{2}$. Fluorinated and other co-polymers are actively used in $\mathrm{O}_{2}$ sensors (Amao, et al., 1999; Amao, Miyashita, \& Okura, 2000; Ishiji, Kudo, \& Kaneko, 1994; Morin, et al., 2000; Puklin, et al., 2000) due to their high chemical and photostability and $\mathrm{O}_{2}$ permeability.

Hydrophilic host polymers such as polyurethane, polyacrylamide, poly(ethylene glycol), show lower $\mathrm{O}_{2}$ permeability and are less suited for fabrication of $\mathrm{O}_{2}$ sensors. Due to 
presence of H-bonding groups (hydroxyl, amino, carboxyl, carboxamide), hydrophillic polymers undergo swelling in water, which affects the $\mathrm{O}_{2}$ calibration under dry/humid conditions (some degree of cross-sensitivity to humidity has also been noted for certain hydrophobic polymeric materials (Kelly, et al., 2014b)). On the other hand, polyurethane hydrogels have been used as binder polymers for incorporating microparticle sensors (Fischer, et al., 2012; Stich, Schaeferling, \& Wolfbeis, 2009). Due to high biocompatibility they also have potential for development of enzyme biosensors based on $\mathrm{O}_{2}$ transducers (Pospiskova, et al., 2013; Schrenkhammer \& Wolfbeis, 2008).

\subsection{Sensor Fabrication Methods}

To ensure fast response and easy access of sample $\mathrm{O}_{2}$ to the dye, the $\mathrm{O}_{2}$ sensing material is usually prepared as thin film coating on a suitable substrate or support material, or integrated directly into food package. The resulting sensor should be stable, produce robust, reproducible and easily measurable luminescent signals and response to $\mathrm{O}_{2}$ concentration. There are several ways through which an $\mathrm{O}_{2}$-sensitive dye can be incorporated in a polymeric matrix.

Commonly, the dye is dissolved in a suitable organic solvent, mixed with a polymer of choice to form a sensor cocktail (or $\mathrm{O}_{2}$-sensitive luminescent ink (Mills, 2005)), which is then applied on a support (polyester film, glass slide, optical fiber tip, etc.) and dried to form solid-state sensor coating. Such method is relatively simple and works satisfactory when the dye and the polymer have similar polarity. However, 'cocktail' methods are associated with large changes in the volume of sensor coating during drying (1:5-1:100), resulting in tension, prominent micro-heterogeneity and relaxation processes within the polymer matrix. Interaction of sensor material with support material and formation of mixed polymer phases can also take place. The processes of coating and drying from a volatile organic solvent are difficult to control precisely, and this leads to significant variability between batches, shift and drift of calibration and compromised analytical performance. These limitations are critical when the sensors are intended for use on a large scale, disposable and calibration-free basis, which is required in many packaging applications. Solvent-based incorporation in hydrophobic polymers does not fully prevent migration and leaching of the dye into the sample and support material (especially for microporous supports with very high contact area). Such undesirable effects can be overcome by covalent coupling of the dye and polymer through functional groups including amine (Borisov, Lehner, \& Klimant, 2011; Wang, et al., 2002; Xavier, et al., 1998), alkene (DeRosa, et al., 2003; Tian, et al., 2010), siloxane (Malins, et al., 1999). Thus, covalent linkage of PtTFPP by 'click' chemistry (Koren, et al., 2012) prevented leakage and migration, while retaining high stability and homogeneous distribution of the dye. The downside of this is increased cost of sensor material.

As alternatives to polymeric cocktail coatings, several other methods and host materials exist for fabrication of $\mathrm{O}_{2}$ sensors. Bulk PE and PP exhibit excellent mechanical properties and moderate $\mathrm{O}_{2}$ permeability. They are widely used in packaging laminates as inner heat-sealable layers (Plastic Films in Food Packaging: Materials, Technology and Applications, 2012). However these polymers are less explored in $\mathrm{O}_{2}$ sensors due to poor compatibility with established fabrication methods (solvent cocktails). Nonetheless, $\mathrm{O}_{2}$ 
sensors have been fabricated from PP and HDPE films by solvent-crazing process, which creates well-developed nanoporous structures within the polymer, which can physically trap various cargo such as $\mathrm{O}_{2}$-sensitive dye molecules (Gillanders, et al., 2010). The resulting sensors based on ordinary polyolefin and phosphorescent porphyrins exhibited useful sensing performance, high brightness, chemical and mechanical stability. More recently, discrete sensor spots were fabricated by localised spot-crazing of HDPE films(Toncelli Claudio, et al., 2014) and PPS film (Kelly, et al., 2015; Toncelli C., et al., 2014), which exhibited linear Stern-Volmer plot in the range of $0-21 \mathrm{kPa} \mathrm{O}_{2}$, mild temperature dependence and crosssensitivity to humidity. Non-woven polyolefin materials (microfibrous PP membranes) were also impregnated with phosphorescent dyes (PtTBP) by swelling in an organic solvent to produce usable sensors showing good sensitivity to $\mathrm{O}_{2}\left(\tau_{0} \sim 50-60 \mu \mathrm{s}, \tau_{21} \sim 22-30 \mu \mathrm{s}\right)$, fast response, wide $\mathrm{O}_{2}$ range $(0-100 \mathrm{kPa})$, brightness and no cross-sensitivity to humidity (Kelly, et al., 2014b).

Incorporation of an $\mathrm{O}_{2}$-sensitive dye into micro and nanoparticles such as cross-linked PS beads has also been explored (Borisov, et al., 2014; Borisov Sergey M., et al., 2009; Chojnacki, Mistlberger, \& Klimant, 2007; Stich, Fischer, \& Wolfbeis, 2010). Such precursor sensor materials can be fabricated by simple and scalable solution method in a powder form, which is then incorporated in a 'binding' polymer (e.g. silicone) to produce sensor coatings. $\mathrm{SiO}_{2} / \mathrm{TiO}_{2}$ microparticles with adsorbed $\mathrm{O}_{2}$-sensitive dye were also extruded into flexible films of common packaging polymers, such as LDPE (Mills \& Graham, 2013). This approach and sensor materials are attractive, as they are compatible with standard industrial processes and facilitate sensor integration in packaging materials.

Sol-gel matrices synthesised through hydrolysis of silane precursors allow encapsulating $\mathrm{O}_{2}$ sensitive dyes and provide optical transparency, good mechanical and chemical stability (Jerónimo, Araújo, \& Conceição B.S.M. Montenegro, 2007). Porosity and $\mathrm{O}_{2}$ sensitivity of the sol-gel can be tuned by parameters such as $\mathrm{pH}$, aging time, water and precursor silane ratio, etc. (McEvoy, McDonagh, \& MacCraith, 1997). Sol-gels can alter their network structure over time, thus affecting sensor calibration and response time. Ormosils containing higher amount of alkyl and aryl groups and exhibiting high oxygen permeability have been used to fabricate $\mathrm{Ru}(\mathrm{II})$-polypyridyl and $\mathrm{Pt}(\mathrm{II}$ )-porphyrin based sensors (Basu, 2007; Chu \& Chuang, 2015; Korzeniowska, et al., 2015; McDonagh, MacCraith, \& McEvoy, 1998). The limitations of sol-gel technology are its reliance on the many ingredients and process parameters, slow speed of polymerisation/setting and the need for 'annealing'.

For packaging applications, fabricated $\mathrm{O}_{2}$-sensors should be incorporated into the packages with foods or integrated in particular packaging materials which are then used on a packaging line. Sensor incorporation and integration options include free-standing sensor inserts placed in containers with food, sensor labels of adhesive stickers attached to or printed on the inner side of the packaging tray or lidding material, sensors laminated inside the packaging material between the barrier and inner heat-sealable layers. The main requirements for the integration are easy access of sample $\mathrm{O}_{2}$ from headspace, liquid or bulk food to the sensor and optical contact with the particular luminescent detector/reader to interrogate with the sensor from a certain distance (usually a few $\mathrm{mm}$ ) and produce reliable readings of $\mathrm{O}_{2}$ concentration. Sensor contact with atmospheric $\mathrm{O}_{2}$ should be avoided, as this will skew the $\mathrm{O}_{2}$ measurements. 
Another role of sensor integration process is to protect sensor material from direct physical contact with the product, and vice versa. This is because some food components (e.g. meat juice, fat, flavours, etc.) can affect sensor characteristics (reduced signals due to colouration, shift calibration due to plasticisation) and thus lead to erroneous $\mathrm{O}_{2}$ readings. A gas-permeable film (PE or PP) laminated on top of the sensor can prevent migration of sensor components (dye, polymer matrix) into food and product contamination with debris which can be accidentally delaminated and ingested. This can improve sensor safety.

\subsection{Sensor Selection and Characterisation}

Many luminescent dyes and $\mathrm{O}_{2}$ sensing materials have been described so far, but only a small number of these (Table 1) have been actually used in packaging applications, i.e. with real food samples and under industrial settings. These materials usually have advantageous $\mathrm{O}_{2}$ sensing performance, spectroscopic properties, availability, costs, scalability of raw materials and manufacturing processes, and compatibility with existing packaging materials and commercial detection instrumentation. The other candidates failed in one or more of these selection criteria, like attrition of leads in drug discovery.

By now Pt(II)-benzoporphyrin dyes excitable at 580-630 $\mathrm{nm}$ and exhibiting near infrared emission at 730-850 $\mathrm{nm}$ look most promising. High brightness, good separation of excitation and emission (Stokes shift $>100 \mathrm{~nm}$ ), narrow bands, moderate quenching by $\mathrm{O}_{2}$ due to relatively short lifetimes ( $\sim 65 \mu$ s unquenched) are their advantages. These dyes are excitable with powerful orange-red LEDs and detectable with silicon photodiodes, which makes the development of lifetime-based $\mathrm{O}_{2}$ sensing instrumentation relatively easy and inexpensive. Their chemical, photo stability and solubility in polymeric matrices are good, synthesis is relatively inexpensive, although more costly than for PtTFPP or sensor dyes without noble metals (Borisov S. M., et al., 2009). Low intrinsic toxicity of these dyes and minute quantities used per sensor $(<1 \mu \mathrm{g})$ make them affordable and safe to use in packaging and with food products. A number of sensor materials based on these dyes have been described, which have simple chemical composition (two-component composites) and fabrication procedure, good analytical performance and reproducibility, general convenience and robustness (Mills, 2005). These materials are suitable for large scale manufacturing and integration in existing packaging systems.

However to implement up-scaling and sizeable deployment in food packaging, prototype $\mathrm{O}_{2}$ sensors should undergo a detailed characterisation of their operational performance, with rigorous testing and comprehensive validation under real-life conditions. Initially, sensor calibration is performed in laboratory settings, measuring lifetime signals from several individual sensors from a batch at different $\mathrm{O}_{2}$ concentrations and temperatures. For general food packaging applications, sensors should normally show stable and reproducible calibrations in the concentration range $0-25 \mathrm{kPa}(0-100 \mathrm{kPa}$ for raw red meat). Most of the solid-state sensors showed dependence on the temperature and sensitivity usually decreases at low temperature, which should be factored in to ensure accurate $\mathrm{O}_{2}$ readings over a wide temperature range $\left(\sim-20^{\circ} \mathrm{C}\right.$ to $+30^{\circ} \mathrm{C}$ for food). Unfortunately, only a few studies have been performed over this temperature range (Papkovsky, et al., 2000). Sensor response time is another critical factor. Use of thin film coatings, microporous membranes with low gas 
diffusion barrier and fast response time are generally desired, especially for on-line monitoring of packaging integrity for a large number of samples (Douglas \& Eaton, 2002; Kolle, et al., 1997). High photostability and long storage and shelf-life stability are other important parameters.

\subsection{Measurement Instrumentation and Commercial Systems}

Several companies currently produce optical $\mathrm{O}_{2}$ sensors and measurement instruments for different industrial applications. Not all of these are usable in core packaging applications, which demand a number of special requirements for the sensors, instrument and measurement mode(s). The main requirements for food packaging applications are:

1) Robust operation with detached $\mathrm{O}_{2}$ sensors. This feature, in turn, implies: i) insensitivity to geometrical alignment of the sensor and the instrument during the measurement; ii) insensitivity to attenuation of the luminescence intensity signal from the sensor by the packaging material and food matrix (sensor staining, sample autofluorescence, light absorption and scattering); iii) ability to measure optical signals at a certain (variable) distance (usually $0-15 \mathrm{~mm}$ ) by hand; iv) ability to measure sensors in packages of variable size and shape, irregular geometry.

2) Use of disposable sensors with large number of test samples under different conditions. This implies: i) adequate sensitivity and range of $\mathrm{O}_{2}$ concentrations: typically 0.03 $-25 \mathrm{kPa}\left(0.03-25 \% \mathrm{O}_{2}\right.$ at normal pressure) or preferably $0.01-100 \mathrm{kPa}$; ii) calibration-free measurements (factory or batch-calibration, stable to the factors listed in 1); iii) high reproducibility with a typical variation across the whole $\mathrm{O}_{2}$ range of $\pm 2-3 \%$ of reading or 150 ppm in the low $\mathrm{O}_{2}$ range; iv) rapid $(<1 \mathrm{~min})$ and robust changes in sensor signal in response to changes in sample $\mathrm{O}_{2}$ concentration.

3) Broad range of working temperatures $\left(-20^{\circ} \mathrm{C}-+50^{\circ} \mathrm{C}\right.$ for the sensors and $0-50^{\circ} \mathrm{C}$ for the instrument). This necessitates automatic compensation of luminescence measurements for variation of sample temperature (by means of a contactless IR T-sensor built in the instrument), and barometric pressure (for flexible packages and readout in $\% \mathrm{O}_{2}$ scale). No cross-sensitivity to humidity (identical calibration in gas and liquid phase), no interference by other species that may be present in samples being measured.

4) Light-weight, portable device - handheld reader, with user-friendly design and software, external data communication and on-site performance validation tools (reference sensors). Fast measurement and signal processing ( $<1 \mathrm{~s}$ per reading), data logging and ID tagging (e.g. bar-coding). Affordable price: $\$ 1-2 \mathrm{k}$ for an instrument (currently $\$ 4 \mathrm{k}-\$ 10 \mathrm{k}$ ) and $<10$ cent for a disposable sensor (currently $>\$ 1$ ).

5) High level of validation of the sensors and measurement device with different types of packaging materials and packaged products tested and independently verified. High safety of the sensor material, its ingredients and processes involved. High storage and operational stability (months-years).

Currently, several commercial systems on the market a large degree fulfil these requirements and are suitable for robust $\mathrm{O}_{2}$ monitoring in food packaging. Their main characteristics are summarised in Table 2. Examples of $\mathrm{O}_{2}$ sensors and measurement instruments are shown in Figures 2 and 3. 
Table 2 Examples of commercial $\mathrm{O}_{2}$ sensor systems

\begin{tabular}{|c|c|c|c|}
\hline Company & Mocon Inc \& Luxcel Ltd. & Oxysense & PreSens GmbH \\
\hline Sensor & OpTech $^{\mathrm{TM}}-\mathrm{O}_{2}$ Platinum & $\mathrm{O}_{2}$ xydots $^{(\mathbb{1}}$ & Pst3 \\
\hline Dyes & PtTBP & {$\left[\mathrm{Ru}(\mathrm{dpp})_{3}\right] \mathrm{Cl}_{2}$} & PtTFPP \\
\hline Forms & $\begin{array}{c}\text { Adhesive stickers } \\
\text { (peelable from a card) }\end{array}$ & $\begin{array}{l}\text { Sensor dots } \\
\text { applied with } \\
\text { silicon glue }\end{array}$ & $\begin{array}{l}\text { Sensor dots applied } \\
\text { with silicon glue }\end{array}$ \\
\hline $\begin{array}{l}\text { Measuring } \\
\text { range }\end{array}$ & $\begin{array}{l}0.001-30 \% \text { permeation mode } \\
(\mathrm{g}) 0.015 \%-25 \% \text { headspace } \\
\text { mode }(\mathrm{g})(0.006-10.5 \mathrm{mg} / \mathrm{L}(\mathrm{l}))\end{array}$ & $0-30 \%$ & $\begin{array}{c}0-100 \%(\mathrm{~g}) \\
(0-45 \mathrm{mg} / \mathrm{L}(1))\end{array}$ \\
\hline Accuracy & $\begin{array}{l} \pm 2 \% \text { or } \pm 150 \text { ppm (whichever } \\
\text { is greatest) }\end{array}$ & $5 \%$ of reading & $\begin{array}{l} \pm 0.4 \% @ 20.9 \% \mathrm{O}_{2} \\
\pm 0.05 \% @ 0.2 \% \mathrm{O}_{2}\end{array}$ \\
\hline Detection limit & $0.03 \%(0.03 \mathrm{kPa})$ & $\begin{array}{c}0.03 \% \text { (gas) } \\
15 \mathrm{ppm} \text { (liquid) }\end{array}$ & $\begin{array}{c}0.03 \% \text { (gas) } \\
15 \mathrm{ppm} \text { (liquid) }\end{array}$ \\
\hline Compensation & $\begin{array}{l}\text { Automatic temperature } \\
\text { (contactless IR sensor) and } \\
\text { pressure compensation }\end{array}$ & $\begin{array}{c}\text { Integrated } \\
\text { temperature and } \\
\text { pressure probes }\end{array}$ & $\begin{array}{c}\text { Integrated } \\
\text { temperature, and } \\
\text { pressure probes }\end{array}$ \\
\hline $\begin{array}{l}\text { Operating } \\
\text { temperature }\end{array}$ & $5-40^{\circ} \mathrm{C}$ & $0^{\circ} \mathrm{C}-70^{\circ} \mathrm{C}$ & $0-50^{\circ} \mathrm{C}$ \\
\hline Response time & $\begin{array}{c}<3 \sec \text { (gas) } \\
<30 \sec \text { (liquid) }\end{array}$ & $<30 \mathrm{sec}$ & $\begin{array}{c}<6 \sec \text { (gas) } \\
<40 \sec \text { (liquid) }\end{array}$ \\
\hline Price per sensor & $\$ 3$ & $\$ 4.30$ & $\$ 33$ \\
\hline
\end{tabular}

A)

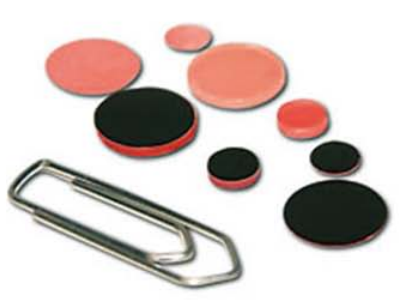

D)

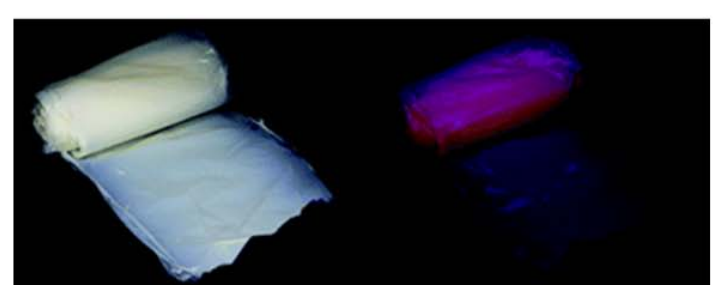

B)

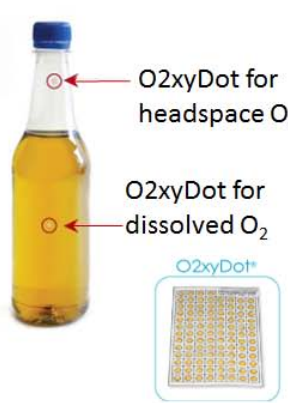

Dot

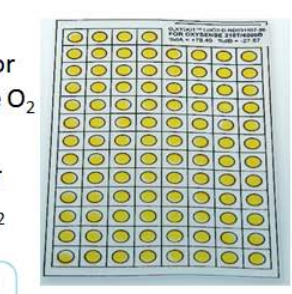

C)

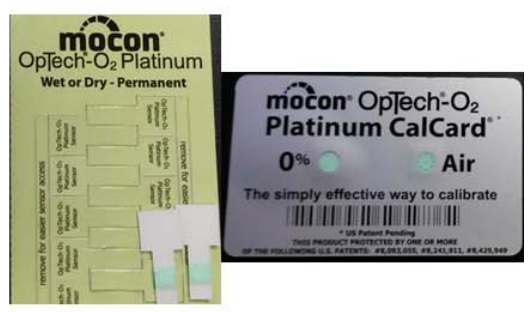

E)

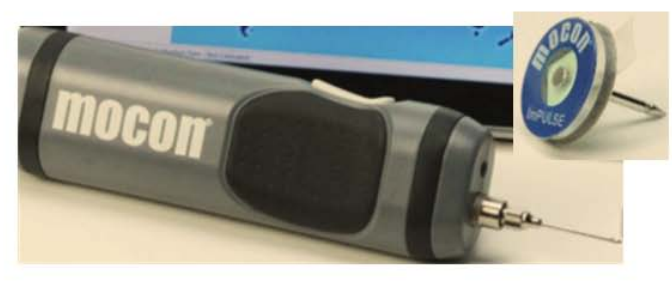

Figure 2. Images of various types of $\mathrm{O}_{2}$ sensors: A) Presens Sensor spots; B) Oxysense sensor spots glued to the bottle; C) Mocon Optech ${ }^{\circledR}-\mathrm{O}_{2}$ Platinum adhesive stickers on a card and CalCard for system validation, D) sheet of extruded sensor film, E) Mocon needle-type and ImPULSE ${ }^{\mathrm{TM}}$ sensors for Optech ${ }^{\circledR}$. $A, B$ and $E$ are reproduced from manufacturer's website. D is reproduced from (Mills \& Graham, 2013), with permission from Royal Society of Chemistry. 

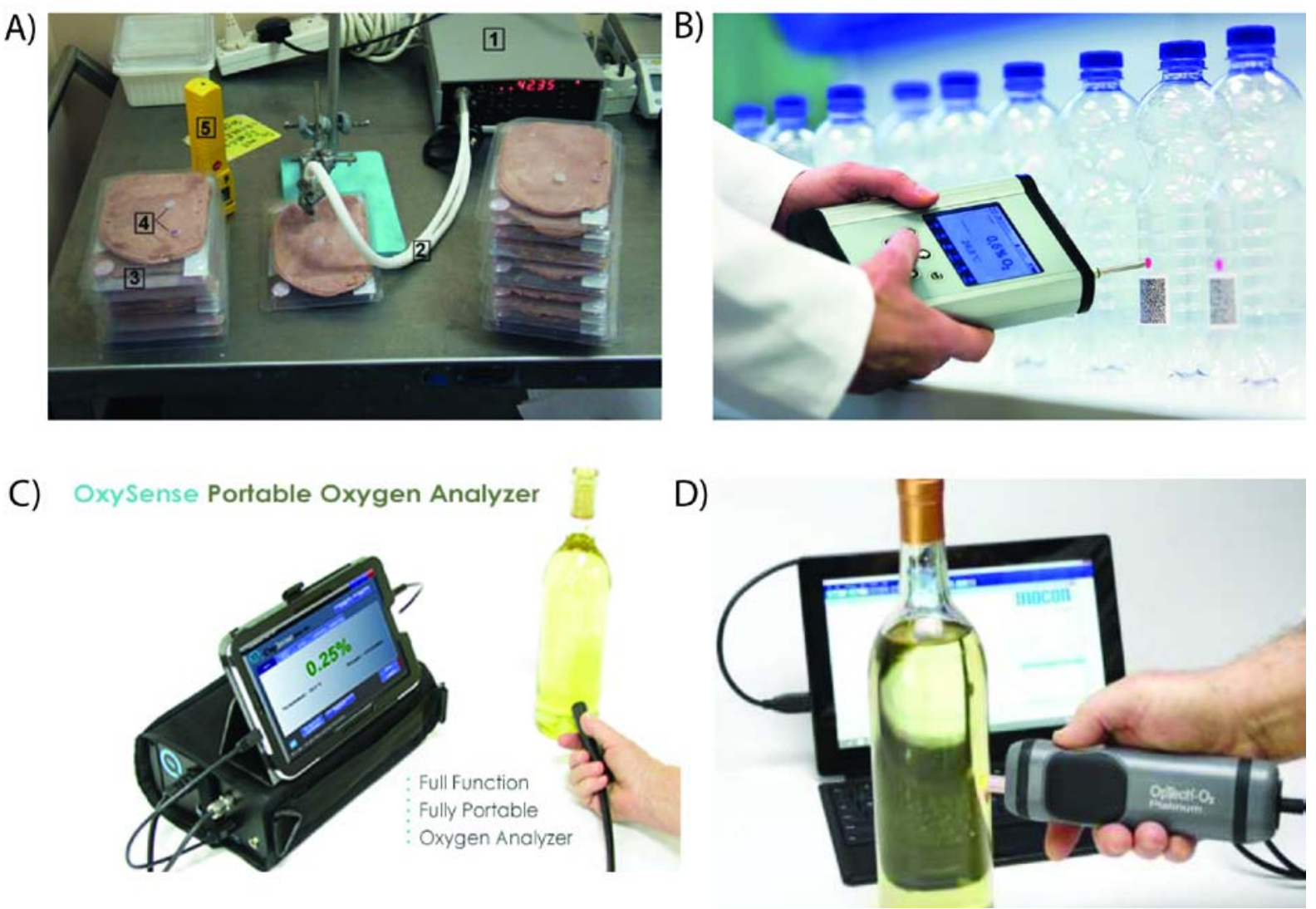

Figure 3. Images of $\mathrm{O}_{2}$ sensing instrumentation: A) One of the first prototypes - fibre-optic phosphorescence phase detector; B) PreSens' Fibox 4; C) OxySense Oxygen analyser; D) Mocon OpTech ${ }^{\mathrm{TM}}$ handheld $^{\circ}$ reader. B-D are reproduced with permission from the manufacturers.

Several other sensor modifications are also offered by these companies. Thus, PreSens provides Pst6 sensors for trace $\mathrm{O}_{2}$ analysis, as well as the dipping fibre optic probe for use in fermentors. The free-standing dOxybead ${ }^{\mathrm{TM}}$ sensors developed by Luxcel are simply dispensed in packs, food samples and beverage bottles, their characteristics are similar to Mocon sensors (Table 2).

The needle-type sensors (PreSens, Mocon, OxySense) and ImPulse ${ }^{\mathrm{TM}}$ sensor pins (Mocon) are designed for destructive measurements. Although less advantageous, this could be the only option for non-transparent packages, such as metal-coated or pigmented film packaging, paper cartons. These sensors are usually used for end-point $\mathrm{O}_{2}$ measurements when package integrity is no longer important, however special rubber septa for the needle probe or adhesive coating on ImPulse ${ }^{\mathrm{TM}}$ sensors allow repetitive measurements, although not over long time periods.

Some sensors require quick re-calibration before use to ensure their accuracy, others are supplied pre-calibrated in batches. PreSens recommend a two point calibration with $0 \mathrm{kPa}$ and $21 \mathrm{kPa} \mathrm{O}_{2}$ gas mixtures for their sensors (Ps3 and others). OxySense $\mathrm{O}_{2} \mathrm{xydot}^{\circledR}$ sensors come with factory calibration, however the user may need to carry out re-calibrations at various conditions, if deemed necessary. The $O \mathrm{pTech}^{\mathrm{TM}}$ sensors come factory-calibrated. Very often sensor characteristics specified on company web site relate to pre-calibrated sensors or one batch of sensors rather than for different batches. In this case, sensor type has to be specified and its calibration parameters loaded in the instrument software. In our experience to date, Mocon sensors provide best reproducibility for disposable sensors, with 
sensor-to-sensor and batch-to-batch variability of $<2 \%$. High reproducibility of sensors also allow Mocon to offer "CalCard" ${ }^{\mathrm{TM}}$ " for validation of the sensor stickers and instrument performance on-site, and simple re-calibration of the system with complex samples such as non-transparent packs or highly absorbing samples or vessels.

Temperature compensation is also realised differently - by independent measurement of temperature and subsequent manual compensation of readings in the software, with a contact T-probe connected to the instrument or by contactless measurement of local temperature at the sensor with a built-in infrared T-sensor. The latter approach is the most accurate, it allows automatic compensation and processing large number of samples which have significant variation in temperature (e.g. refrigerated samples measured at ambient temperature).

Barometric sensors built into the instrument allow compensation of optical readings for variation of atmospheric pressure. This enables conversion of primary $\mathrm{O}_{2}$ readings (sensor normally measures $\mathrm{kPa}$ or $\mu \mathrm{M}$ of $\mathrm{O}_{2}$ ) into $\% \mathrm{O}_{2}$, which more common for food industry. Measurement of $\% \mathrm{O}_{2}$ in pressurised containers (wine bottles) still remains challenging.

Easy incorporation of the sensors into food packaging is a must. Pst3 and Oxydot ${ }^{\circledR}$ sensors must be adhered to the packaging with silicone glue, which can often be pernickety and adds to experimental set-up time. In contrast, $\mathrm{OpTech}^{\mathrm{TM}}$ sensors come as self-adhesive stickers on a card, which are easy to handle and attach. The adaptability of $\mathrm{O}_{2}$ sensors and flexible handheld instrumentation allow their use in various applications, including monitoring $\mathrm{O}_{2}$ during processing, transportation and storage. Although useful and fit-forpurpose, the above sensors still have the drawback of being quite expensive, limiting their inclusion and use in mass scale manufacturing. To be viable for routine packaging applications, each sensor must cost less than 10 cent (Mills, 2005).

To address these challenges, many studies are carried out to create less expensive $\mathrm{O}_{2}$ sensor solutions. We believe that this can be realised on the basis of existing phosphorescent dyes, $\mathrm{O}_{2}$-sensing materials, fabrication processes, integration approaches and reading equipment. High demand in non-destructive $\mathrm{O}_{2}$ sensing and packaging applications may also lead to the creation of entirely new $\mathrm{O}_{2}$ sensor materials and systems.

\section{Applications of $\mathrm{O}_{2}$ Sensors in Food Packaging}

\subsection{Monitoring residual (headspace) $\mathrm{O}_{2}$ in packaged foods}

The proof of concept work on the non-destructive luminescence based $\mathrm{O}_{2}$ sensing in food packaging was done in 2000s. Prior to the appearance of commercial $\mathrm{O}_{2}$ sensor systems such as Fibox (PreSens), Oxygen analyser (OxySense) and Optech ${ }^{\mathrm{TM}}$ (Mocon), more primitive though well performing $\mathrm{O}_{2}$ sensors and instruments (phosphorescence phase detector - see Figure. 3 (Ogurtsov \& Papkovsky, 1998)) were mainly used.

Initially, sensors comprised of phosphorescent PtOEPK dye dissolved in polystyrene and spotted on polymeric membrane or filter paper were used to track $\mathrm{O}_{2}$ levels in vacuum packed chicken meat (Papkovsky, et al., 2000) and in MAP chicken, beef and ham samples (Papkovsky, et al., 2002; Smiddy, et al., 2002). In both the vacuum and MA packaged samples, when the sensors were placed on top, in direct contact with the product, reliable optical signals and quantitative measurements of $\mathrm{O}_{2}$ were obtained for the food samples they 
were exposed to. However, for vacuum packaged samples the sensor was seen to provide inadequate information about global $\mathrm{O}_{2}$ levels and package integrity, because in such shrunken packs without any headspace, diffusion of $\mathrm{O}_{2}$ laterally and from the bulk of the product is largely reduced. As a result, unless some air was able to enter and swell the pack, the sensor could not detect compromised integrity (cuts or punctures in packaging materials at distant sites from the sensor, $>1 \mathrm{~cm}$ ). Therefore, wider use of $\mathrm{O}_{2}$ sensor dots in vacuum packaged products as a QA tool was hardly justifiable.

In contrast, for MAP products the use of disposable $\mathrm{O}_{2}$ sensors in individual packs was found to be very useful and informative. The sensors placed on top of the food or underneath the lidding and exposed to package headspace were able to: i) quickly scan for residual $\mathrm{O}_{2}$ levels medium and large batches (10s - 100s of packs, each measured in 1-5 s); ii) reliably quantify actual $\mathrm{O}_{2}$ concentration in each pack, determine mean values and variability within the batch; iii) detect outliers and faulty packs with headspace $\mathrm{O}_{2}$ exceeding predicted values for this product; iv) monitor dynamics of headspace $\mathrm{O}_{2}$ concentration over product shelf life; v) pick up the appearance of new faulty packs by repetitive measurements (Figure 4); vi) assure general compliance (or not) to product specifications of each pack, whole tested batch and corresponding products and manufacturing processes used.
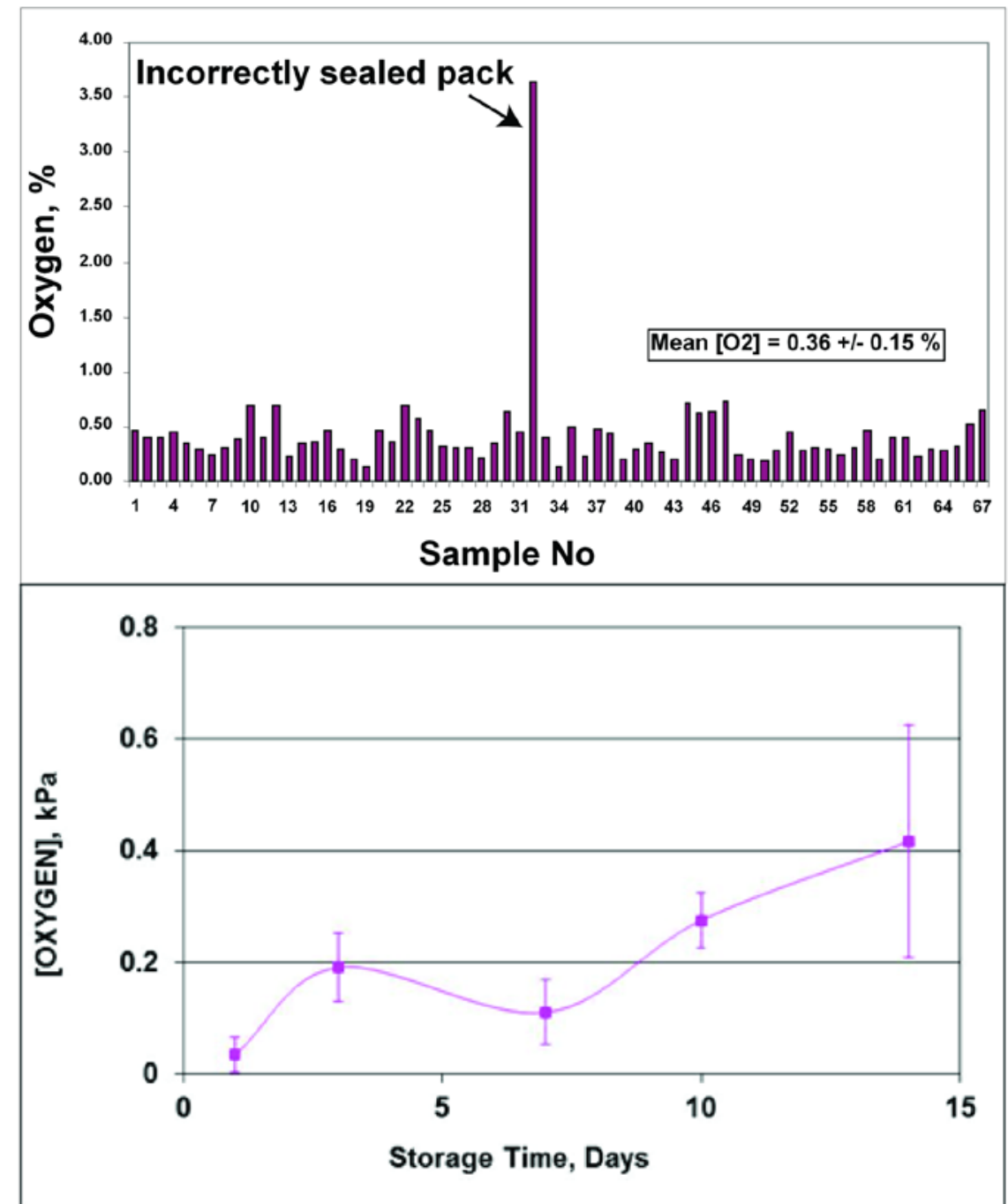

Figure 4. Representative results of screening of a batch of MAP food product with disposable $\mathrm{O}_{2}$ sensors (top) and changes in headspace $\mathrm{O}_{2}$ in MAP ham packs over storage at $4^{\circ} \mathrm{C}$ (bottom). 
This sensing approach was subsequently applied to many other MAP food types including raw and cooked meat, smoked fish, bread, convenience foods (lasagne)(Fitzgerald, et al., 2001). Samples of MAP cheddar cheese (high fat product) were also checked for integrity via Pt-OEPK sensors which revealed a number of faults in the process and packaging material and allowed their troubleshooting and optimisation (O'Mahony, et al., 2006). The need for leak checking in such products was evident, as the study found $\sim 5 \%$ faulty packs (three out of 70). Otherwise, poor quality of packaging may lead a large amount of waste, financial losses and loss of reputation for the manufacturing companies.

These initial studies have also demonstrated the applicability of the $\mathrm{O}_{2}$ sensors in industrial settings on production lines with commercial products (sliced MAP hams), and the need for repetitive testing of MAP packages (Papkovsky, et al., 2002). Although the products were packaged under anoxic atmosphere, residual $\mathrm{O}_{2}$ levels in packs were significantly higher (0.1-1\%) and gradually increased during storage. This is due to the factors such as $\mathrm{O}_{2}$ trapping by the food product, exchange with headspace, permeability of the packaging materials to atmospheric $\mathrm{O}_{2}$ and imperfect sealing. Screening showed multiple failures in packaging (1-5 bad packs in each batch) which could be easily missed using the traditional headspace analysers with random once-off destructive measurements throughout a batch. Commercially, early discovery of these failures could reduce waste and financial losses, as when the leakage is discovered the food could be repackaged without harmful effects on its quality. Thus the $\mathrm{O}_{2}$ sensors potentially allow $100 \%$ quality control in sizeable batches of products and (where feasible and justifiable commercially) integration in each MAP pack. More thorough testing with $\mathrm{O}_{2}$ sensors can help avoid massive product recalls.

\subsection{Food research and quality assessment}

After initial food packaging tests were proven successful, researchers began to use $\mathrm{O}_{2}$ sensors to monitor and characterise various products, assess their quality, shelf-life behaviour and troubleshoot problems with packaging. Thus, OpTech ${ }^{\mathrm{TM}}$ sensors have been used to measure the depletion of $\mathrm{O}_{2}$ in raw beef and chicken fillets (Morsy, April 2014) packaged under $21 \% \mathrm{O}_{2}$ in the headspace. The beef and chicken showed a depletion of oxygen over a 9 day and 10 day period respectively, which corresponded to the food spoilage by aerobic bacteria, which consumed the headspace $\mathrm{O}_{2}$. PtOEPK sensors were used to chart the $\mathrm{O}_{2}$ profile of a faulty package of cheddar cheese, showing its compromised resistance to microbial spoilage and mould growth (Figure 5A) (O’Mahony, et al., 2006).

Fresh produce, such as vegetables and salads, are highly perishable and 'breathable' products. Since these products are alive and respiring after harvesting, they require quick processing, customised packaging and storage (Borchert, et al., 2012) in order to maintain acceptable quality and shelf life. A specific $\mathrm{O}_{2}$ content in MAP and perforation of the lidding are required for the respiration to occur and to maintain low enough $\mathrm{O}_{2}$ levels that discourage the growth of microorganisms. High throughput non-destructive $\mathrm{O}_{2}$ sensing with Mocon OpTech $^{\mathrm{TM}}$ system successfully addressed these issues and accelerated the development of improved packaged products (Hempel Andreas, et al., 2013). It provided accurate and reliable checking of $\mathrm{O}_{2}$ levels within packaged fresh salad leaves and generation of respiration 
profiles (Figure. 5B). Different lettuce types showed different respiration and $\mathrm{O}_{2}$ requirements in MAP to achieve a shelf-life of seven days.

PtOEPK sensors were used during the testing of different ethanol based atmosphere modifiers on MAP bread (Hempel AW, et al., 2013). The purpose was to prolong shelf life of commercial ciabatta bread without compromising palatability. The sensors showed that although the products were packaged with an $\mathrm{O}_{2}$-free atmosphere, their $\mathrm{O}_{2}$ levels rose to approximately $14 \%$ as a result of the diffusion of $\mathrm{O}_{2}$ stored in the bread structure. This encouraged the growth of mould, seen by day 12 of storage. The use of ethanol spray offset the physical appearance of mould, but only for one day and also imparting a disagreeable flavour to the product. In contrast, the ethanol-emitting LDPE sachet delayed mould growth onset up until day 30 of storage, without imparting undesirable aromas and flavours onto the product. This study with $\mathrm{O}_{2}$ sensors showed promise of ethanol emitters for the prolongation of shelf-life.

Colour, taste and aroma are important parameters on which food is evaluated by producers and consumers. Residual $\mathrm{O}_{2}$ can have a major effect on these parameters and the quality of the finished product. Therefore, the monitoring of $\mathrm{O}_{2}$ and correlation with the degradative processes occurring in foods is vital in predicting shelf-life and ensuring quality aspects. In a study on the lipid oxidation, samples of raw and cooked vacuum-packaged and MAP beef were assessed with $\mathrm{O}_{2}$ sensors (Smiddy, et al., 2002). Figure 5C-D show that vacuum-packed raw and cooked meats were stable to oxidation until day 35, while MAP meat which had a higher level of $\mathrm{O}_{2}$, had an oxidative stability of 12 days. The oxidation in the MAP cooked beef was slightly lower than that in the vacuum-packed cooked beef, implying that although some $\mathrm{O}_{2}$ is needed for lipid oxidation, it is not the driving factor. The cooked meats showed higher lipid oxidation than the raw meat, showing that high temperatures drive the oxidation procedure. Thus, efforts must be made to limit $\mathrm{O}_{2}$ exposure in the period between cooking and packaging. 
A)

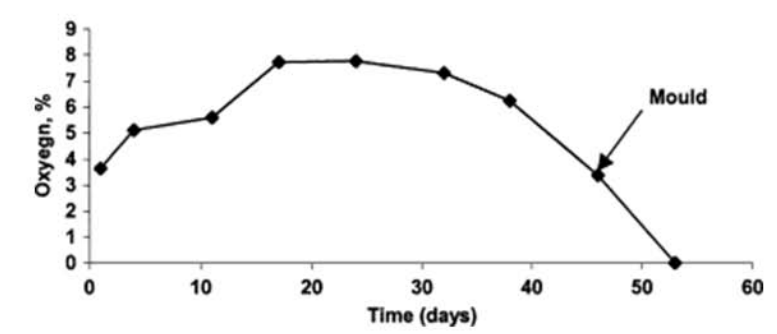

C)

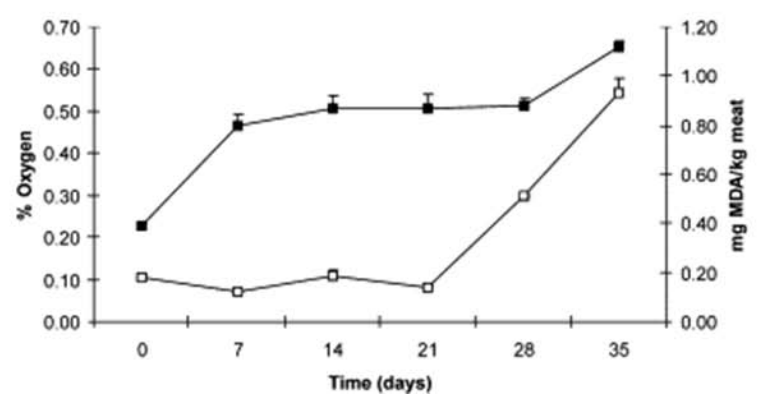

B)

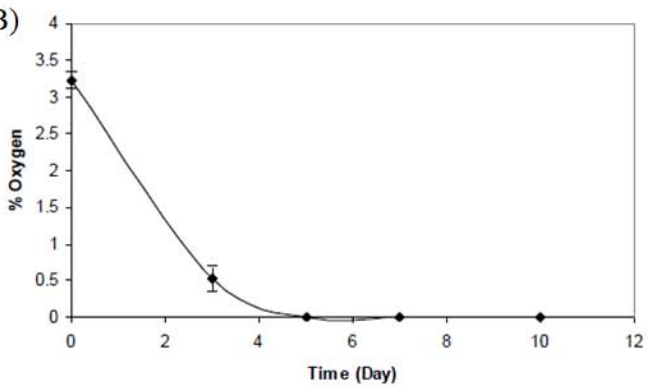

D)

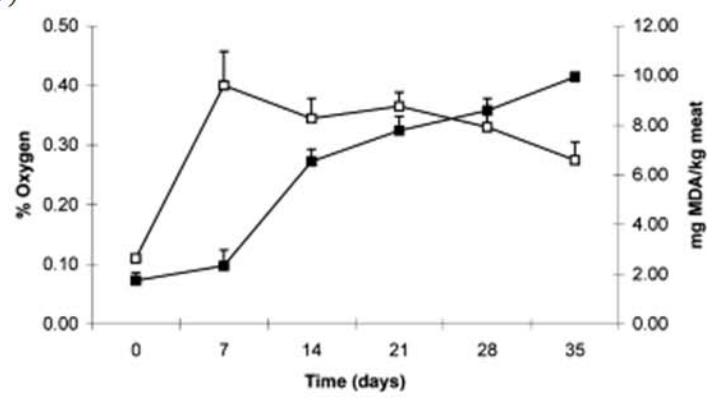

Figure 5. Representative $\mathrm{O}_{2}$ profiles: A) an improperly packaged cheese sample (arrow shows appearance of mould), B) mean $\mathrm{O}_{2}$ levels $(n=12)$ in commercial packages with salad leaves, $\left.C\right)$ and D) $\mathrm{O}_{2}$ content and lipid oxidation in raw vacuum packed meat and cooked vacuum packed meat respectively. () represents the \% of $\mathrm{O}_{2}$ and (G) - lipid oxidation in $\mathrm{mg}$ MDA $/ \mathrm{kg}$ meat. A) Reproduced from (O'Mahony, et al., 2006) with permission from Elsevier B) from (Hempel Andreas, et al., 2013) with permission from MDPI. C and D Reproduced from (Smiddy, et al., 2002) with permission from Elsevier.

Packaging of food products under MAP conditions with right composition of $\mathrm{O}_{2}$ and $\mathrm{CO}_{2}$ gases in combination with refrigeration temperature appears an efficient approach to decrease microbial contamination and preserve the quality of food products. Recent studies have suggested (Amanatidou, Smid, \& Gorris, 1999; Van der Steen, et al., 2002), MAP should have elevated levels of $\mathrm{O}_{2}(>70 \%)$ and $\mathrm{CO}_{2}(10-20 \%)$ to reduce the growth of spoilage microorganisms, prevent various anoxic processes and maintain the natural freshness, taste and appearance of green produce (salads, vegetable or fresh cut fruits). In this context, parallel analysis of headspace $\mathrm{O}_{2}$ and microbial load in MAP products can provide valuable information. This was demonstrated by the combined use of Optech ${ }^{\mathrm{TM}} \mathrm{O}_{2}$ sensor system for non-destructive headspace $\mathrm{O}_{2}$ measurement and GreenLight ${ }^{\circledR}$ system (Mocon-Luxcel, also based on the optical $\mathrm{O}_{2}$ transducer) for rapid determination microbial load in the various ready-to-eat MAP salad samples (Borchert, et al., 2012). The GreenLight test provided monitoring of microbial load over the period of storage by destructive sampling, which is a convenient replacement to the tedious agar plating technique (ISO4833:2003). The combined use of Optech ${ }^{\mathrm{TM}}$ and GreenLight ${ }^{\mathrm{TM}} \mathrm{O}_{2}$ sensor technologies provide a versatile platform for high throughput assessment of microbial safety and quality of food products, optimisation of packaging and shelf-life studies of MAP products.

\section{3. $\mathrm{O}_{2}$ sensing in liquid products and beverages}

As well as controlling some chemical reactions in foods, dissolved $\mathrm{O}_{2}$ plays a key part in liquid products and beverages. In particular, many chemical reactions occur during maturation of red wine and $\mathrm{O}_{2}$ has either beneficial or negative effect on final wine characteristics. Therefore, $\mathrm{O}_{2}$ content in the wine must be controlled and optimized. In a 
proof of concept study, PtTBP based sensors were applied to green and brown coloured wine bottles to detect $\mathrm{O}_{2}$ leaks (Müller, et al., 2015), which showed that they can monitor integrity of capped bottles and track the ingress of $\mathrm{O}_{2}$ via their closures.

Many wine-makers are adding $\mathrm{O}_{2}$ in a controlled manner in order to optimize the maturation. The influence of different $\mathrm{O}_{2}$ exposures on the evolution of volatile sulphur compounds (VSCs), including $\mathrm{H}_{2} \mathrm{~S}$, methyl mercaptan (MeSH) and ethyl mercaptan (EtSH), during maturation of Shiraz Red wines was investigated with the aim to control $\mathrm{O}_{2}$ procedures and the development of VSC in the wines (Ugliano, et al., 2012). In another study, the bottles were fitted with two Pst 3 sensors to measure dissolved and headspace $\mathrm{O}_{2}$. It showed that $\mathrm{O}_{2}$ had a direct effect on the $\mathrm{H}_{2} \mathrm{~S}$ and MeSH levels, which in turn affected the odour of the wine. This data revealed a relationship between $\mathrm{O}_{2}$ levels and accumulation of VSCs.

To combat oxidative degradation ascorbic acid is added to white wine (Wallington, et al., 2013), which has been shown to improve flavour and colour. The undesirable by-products from the ascorbic acid are usually scavenged by the sulphur dioxide present in the wine, preventing their effects on wine quality (Bradshaw, et al., 2011). If not controlled, these processes can potentially deplete sulphur dioxide which provides antimicrobial protection to the wine and extends shelf-life.

The PreSens PSt3 and PSt6 sensors were used to measure headspace and dissolved $\mathrm{O}_{2}$, respectively, and gather kinetic data on the non-oxidative degradation of ascorbic acid. Although conditions were not pure anoxic, $\mathrm{O}_{2}$ concentrations were maintained $<50 \mu \mathrm{g} / \mathrm{L}$, i.e. below quality control capabilities of the wine industry and the limit of detection of the PSt3 sensors (V. O'Brien, 2009). The results showed that lower temperatures were more effective at inhibiting ascorbic acid degradation. Therefore, the storage and transport of wines should not expose them to elevated temperatures. Other studies with PSt3 and PSt6 sensors and the Fibox 3 were to ascertain the routes of $\mathrm{O}_{2}$ ingress and the main chemicals reactions affecting the character of wines. If $\mathrm{O}_{2}$ is too low, aroma defects such as dominant smell of egg, rotten vegetables accompanied by fruity undertones (Mestres, Busto, \& Guasch, 2000) can occur. On the other hand, excess of $\mathrm{O}_{2}$ can enhance oxidation and discoloration of the wine (Salmon, 2006).

PreSens optical dipping probe was also used to assess dissolved $\mathrm{O}_{2}$ concentrations influenced by the pump-over operations during wine production(Moenne, et al., 2014). As expected the closed pump-over systems showed no increase in $\mathrm{O}_{2}$ while for the open set-ups extra $\mathrm{O}_{2}$ was integrated into the wine. In addition, depending on the depth at which the reading was taken, the $\mathrm{O}_{2}$ concentrations in production vats varied greatly, which implies that uneven oxygenation during processing can lead to a heterogeneous product.

Excessive $\mathrm{O}_{2}$ added to wine can also detrimentally change its colour (white wine can turn brown and red wine can turn an orange-red hue), and controlled oxygenation can help to control this (McRae, et al., 2015). $\mathrm{O}_{2}$ is normally added after fermentation, however $\mathrm{O}_{2}$ sensors were used to monitor the $\mathrm{O}_{2}$ concentration of Shiraz wines made with rotary fermenters and treated with different oxygen levels (McRae, et al., 2015). From this data, correlations were made between higher $\mathrm{O}_{2}$ concentrations and more stable wine colour and a 
lower tannin concentration which in turn leads to lower wine astringency. Both parameters increase the desirability of wines to consumers.

Like wine, flavour and visual appearance of beer are dependent on oxidation during processing and packaging (Hempel A., et al., 2013). The lower the oxidation, the more stable the beer flavour. After fermentation, beer should be completely free of $\mathrm{O}_{2}$, however it is most prone to oxidation at this point. Bottles are filled up to the top with carbonated beer and then capped aiming to minimise $\mathrm{O}_{2}$ trapped in the bottles. However, the bottling process is affected by the different foam structures formed in bottle necks which trap some $\mathrm{O}_{2}$. As shown by monitoring of $\mathrm{O}_{2}$ in bottles of pasteurised beer with $\mathrm{O}_{2}$ sensors, high residual $\mathrm{O}_{2}$ levels in headspace lead to higher levels of carbonyls and development of undesirable taste during storage (Hempel A., et al., 2013). The study also showed that pasteurization caused headspace $\mathrm{O}_{2}$ to diffuse into the product and then release back. Sensory analysis showed that beers with an initially high headspace $\mathrm{O}_{2}(>1 \%)$ were deemed unacceptable by the beer tasting panel. Therefore, $\mathrm{O}_{2}$ sensors can be used as quality check and to set up a $\mathrm{QC}$ tolerance level for headspace $\mathrm{O}_{2}$ in bottled and pasteurised beer.

Packaged juices are also highly perishable and $\mathrm{O}_{2}$ sensitive products, and their residual $\mathrm{O}_{2}$ is an important quality factor in the production and storage. Thus, orange juice contains high amounts of ascorbic acid (AA, or vitamin C) as stabilising anti-oxidant, which is oxidized over time into L-dehydroascorbic acid which has an 5 times lower antioxidant activity (Nkhili \& Brat, 2011). The residual $\mathrm{O}_{2}$ and the permeability of the packaging have an impact on the nutritional qualities of the juice and its oxidative browning. Oxydot ${ }^{\circledR}$ sensors were used to link headspace $\mathrm{O}_{2}$ levels to the degradation of AA (Van Bree, et al., 2012; Wibowo, et al., 2015), showing that DHA was formed more rapidly and at greater quantities at higher $\mathrm{O}_{2}$ levels. Therefore, $\mathrm{O}_{2}$ should be controlled during processing and packaging of orange juice to ensure that undue degradation does not occur.

The connection of storage temperature and lipid oxidation in rapeseed oils was examined using Oxydot ${ }^{\circledR}$ sensors. They showed that elevated temperatures increase $\mathrm{O}_{2}$ consumption leading to higher levels of peroxide formation in oil stored under air headspace (Kozak \& Samotyja, 2013), wherea samples stored with nitrogen headspace showed little peroxide formation. Thus, the $\mathrm{O}_{2}$ measurement could be applied to work out optimal storage conditions for oils.

\section{4. $\mathrm{O}_{2}$ permeation measurements}

In MAP systems a gradient of the gas is created between the inner compartment with food and external atmosphere (usually air). The permeation of packaging materials, even with high-barrier properties, is still significant and passes atmospheric $\mathrm{O}_{2}$ into the product. Therefore, measurement of gas permeability of packaging materials is of critical importance for the food and packaging industry.

The $\mathrm{O}_{2}$ permeability of films and other materials is measured on special instruments such as Mocon's Ox-Tran ${ }^{\circledR}$ Model 2/21 system and Oxysense's Oxyperm OTR System. In the Ox-Tran ${ }^{\circledR}$, films are placed in a diffusion chamber, purged with nitrogen, and then permeation of $\mathrm{O}_{2}$ through the film from the outside of the cell (air or $\mathrm{O}_{2}$ atmosphere) is monitored (MOCON). Although very accurate, this method is slow, has low sample 
throughput and usually operates with planar unprocessed samples and in gas/gas phase system.

Introduction of disposable $\mathrm{O}_{2}$ sensors and non-destructive contact-less optical measurements can address these shortcomings and enable an extended panel of gas permeation tests. The sensors can be adhered to almost any surface of the pack, be used to measure $\mathrm{O}_{2}$ permeability of packaging materials which were stressed on the packaging line (whole chain of steps: thermoforming, filling, sealing, labelling/printing and mechanical handling, etc.). Flexible and versatile $\mathrm{O}_{2}$ sensor technology allows permeation measurements in various shapes of packs, including whole composite material (e.g. trays with sealed lidding, bottles with closures, package filled with liquid or food simulant. Also gas exchange can occur between the headspace and food products (see above).

In our early study with the phase detector and PtOEPK-PS sensors, we compared $\mathrm{O}_{2}$ permeation of commercial PE/PP yoghurt bottles having different size (Figure 6). PET carboys used in home winemaking and brewing were evaluated for $\mathrm{O}_{2}$ permeability using a OpTech $^{\mathrm{TM}}$ instrument (Gibbs, 2013). The OpTech ${ }^{\mathrm{TM}}$ stickers were adhered to the neck of each carboy and scanned regularly for $\mathrm{O}_{2}$ content. The study affirmed the suitability of BetterBottle PET carboys for home-brewing as they allowed minimal oxygen transfer. A similar study was carried out using PreSens Fibox 3 oxygen meter and PSt6 sensors which were adhered to the glass bottle with silicone glue, and used to compare the $\mathrm{O}_{2}$ ingress into the bottles with different Normacorc closures co-extruded from low density polyethylene over 250 days (Diéval, Vidal, \& Aagaard, 2011). For comparison, the bottle necks were cut, corked and permeability was measured by the Mocon Ox-Tran ${ }^{\circledR}$ instrument. The $\mathrm{O}_{2}$ sensor performed well against the Ox-Trans and was shown to be a viable simple-to-use alternative for $\mathrm{O}_{2}$ permeability measurements. The Oxyperm System has been adapted for measuring $\mathrm{O}_{2}$ permeability of PET bottles, but the instrument is expensive and requires training to use (Oxysense). 


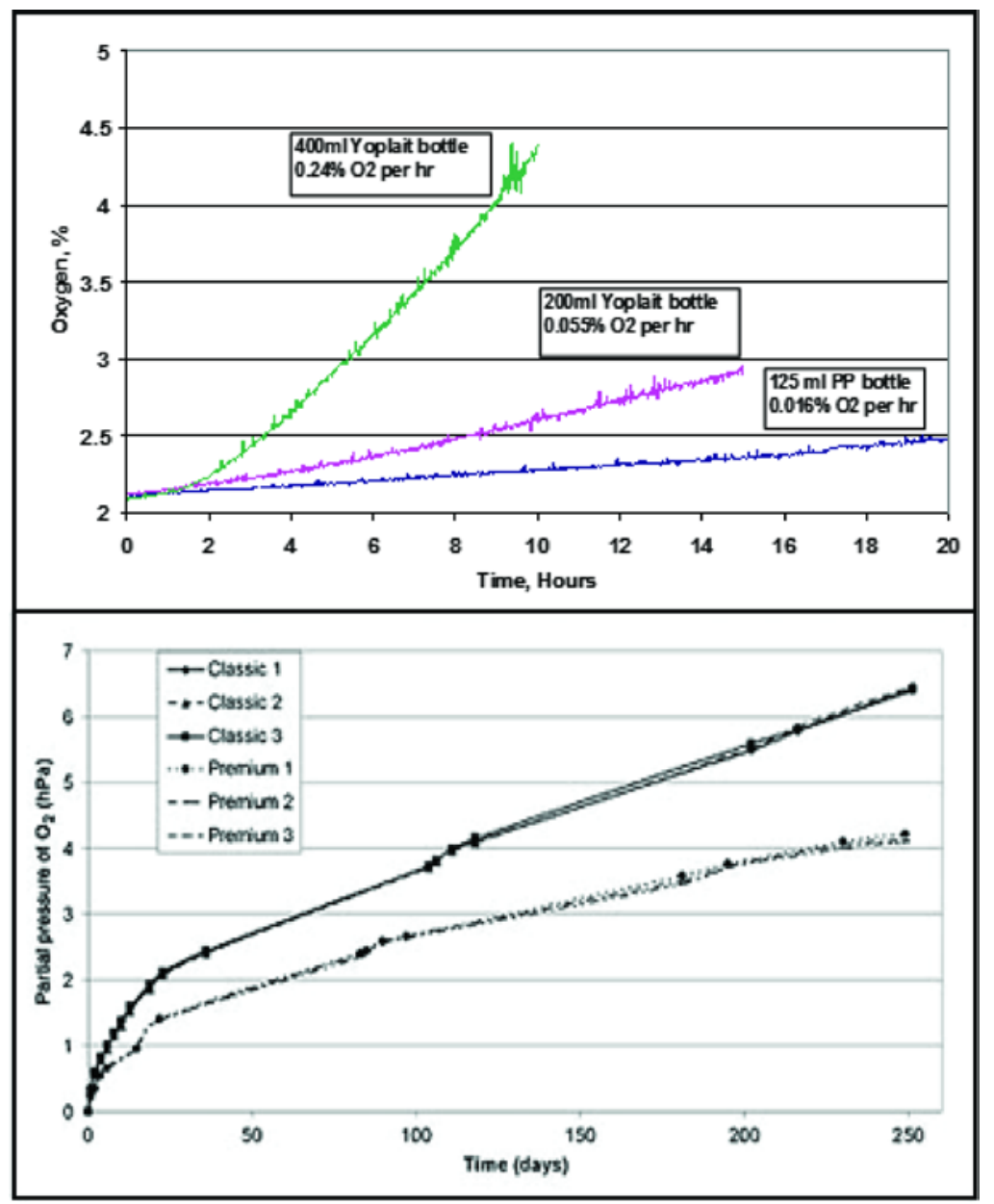

Figure 6. $\mathrm{O}_{2}$ ingress kinetics through plastic yoghurt bottles (top, our unpublished data) and the Classic and Premium Normacorc closures (bottom, reproduced from (Diéval, et al., 2011) with permission from Wiley), measured with optical $\mathrm{O}_{2}$ sensors.

$\mathrm{O}_{2}$ has been shown to enter wine products by way of their closures. The effect of different types of closures and different storage conditions (i.e. glass bottles vs. stainless steel drums) on the coloration of Grénache rosé wines were studied (Wirth, et al., 2012), in which the samples were monitored with Fibox instrument and Pst3 and Pst6 sensors fitted inside the wine bottles (Ugliano, et al., 2011).

A study on the permeation levels of different multilayer packaging compositions, has led to the development of simulation software to predict the optimum headspace $\mathrm{O}_{2}$ concentration in different packaging configurations and storage conditions (Van Bree, et al., 2010). Validation of this software was achieved with the assistance of Oxydots ${ }^{\circledR}$. This software could help to eliminate some of the testing of packaging materials needed for new food products.

\subsection{Validation of $\mathrm{O}_{2}$ sensors, stability and safety in contact with food products}

Despite the existence of several commercial $\mathrm{O}_{2}$ sensor systems and significant number of studies and publications with disposable $\mathrm{O}_{2}$ sensors, the level of their validation and benchmarking against alternative methods (also against each other) is far from being comprehensive. Mocon OpTech ${ }^{\mathrm{TM}}$ system, which has a manufacturer's range of $0-30 \%$ oxygen was compared to the destructive headspace analyser Dansensor which has a range of 
$0-100 \%$ oxygen and carbon dioxide and punctures the package through a septum in order to analyse the headspace (Borchert, et al., 2012). The study showed good agreement of values even up to $40 \% \mathrm{O}_{2}$, after which the $\mathrm{OpTech}^{\mathrm{TM}}$ started to show inaccurate readings. However Optech performed better in the low $\mathrm{O}_{2}$ range showing sensitivity of $0.03 \%$ as opposed to $0.1 \%$ for the Dansensor (Dansensor).

The existing $\mathrm{O}_{2}$ sensors are generally stable. However, very few studies have looked in detail at possible changes in sensor behaviour and calibration upon its exposure to food products of liquid samples in packs. In many cases, sensor stability, accuracy of $\mathrm{O}_{2}$ readings, robustness in conditions of real life operation with different types of packaged foods and beverages remain open questions. This knowledge is particularly important when sensors are operating in direct physical contact with food product that may have high content of fat (plasticisation by oil), strong flavours (cross-sensitivity to gaseous quenchers), variable water content (dry/humid conditions), or long-term experiments with liquid samples. There are multiple reports that package environment and food matrix can negatively affect sensor calibration (shift or drift) and this, if not compensated, may lead to significant errors in $\mathrm{O}_{2}$ readings (Eaton \& Douglas, 2002; Kelly, et al., 2014a). Even if the sensor is protected from contact with the product by an $\mathrm{O}_{2}$ permeable coating (e.g. PE lamination), this does not guarantee the absence of interferences, since water vapour, flavours and gaseous metabolites can still penetrate. Some examples of 'bad' and 'good' sensors are shown in Figure 8.

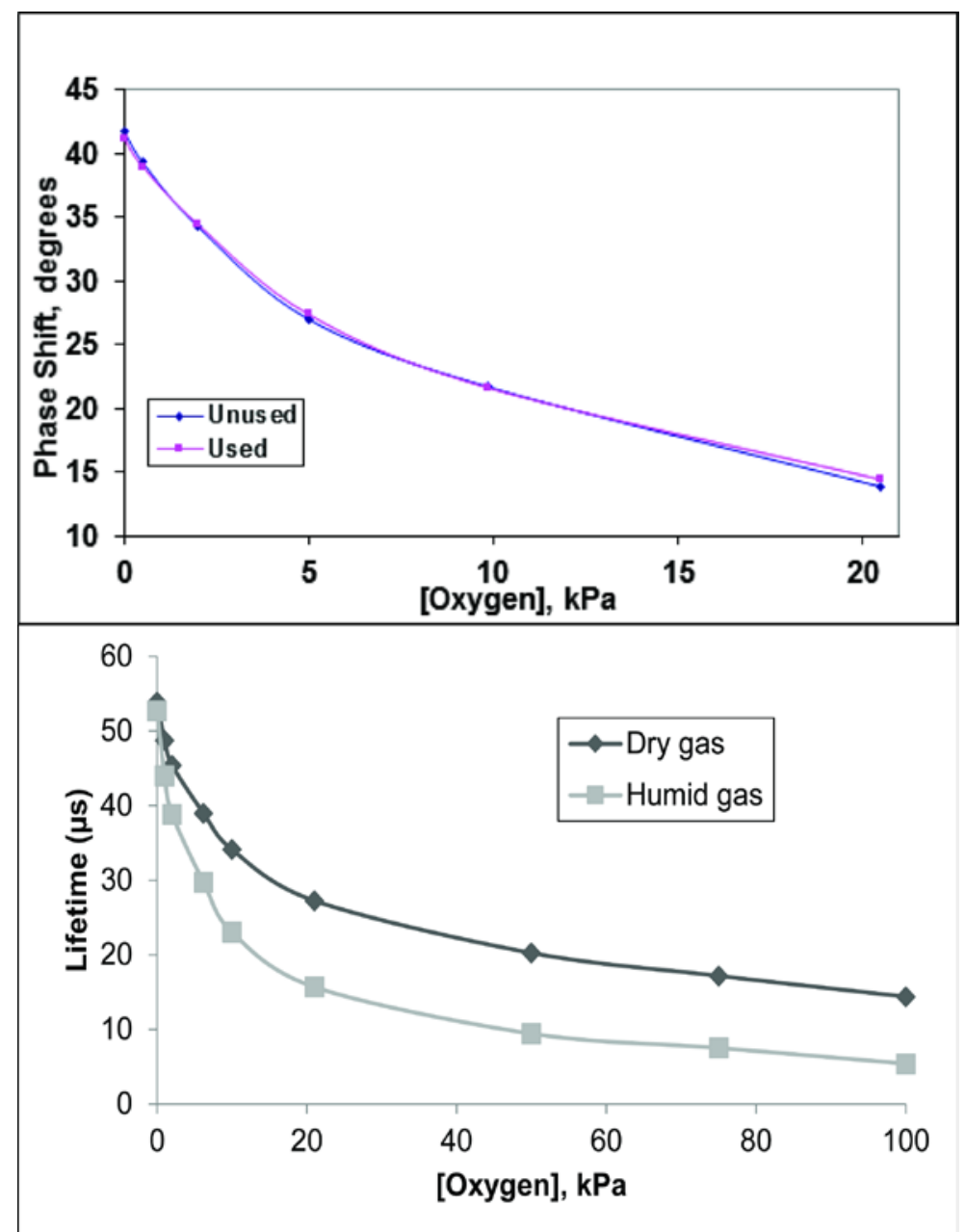


Figure 7. Effect of contact with food (MAP meat) on the calibration of the PtOEPK-PS sensors (top) and cross-sensitivity of a PtTBP-PP sensor to humidity (bottom). Reproduced from (Kelly, et al., 2014a) with permission from Elsevier.

Quite often operational performance and specifications of disposable $\mathrm{O}_{2}$ sensors provided by the manufacturers, especially limits of detection, accuracy, temperature effects, potential interferences, do not match the actual values achieved in packaging applications. As stated above, these specifications often relate to sensors calibrated in situ by an operator, rather than to batches of factory-calibrated sensors. Head to head comparison of different types of commercial $\mathrm{O}_{2}$ sensors and instruments with the same packaged products and conditions frequently reveals significant differences in $\mathrm{O}_{2}$ values that they produce (our unpublished data). Some of the published data on the absolute $\mathrm{O}_{2}$ levels in certain MAP food products and beverages can also be questioned. This situation raises concerns about accuracy and validity of measurements with such sensors. On the other hand, relative $\mathrm{O}_{2}$ values between different conditions/products, $\mathrm{O}_{2}$ trends and profiles measured with different $\mathrm{O}_{2}$ sensor systems are more trustful.

The ever increasing use of disposable sensors and non-destructive $\mathrm{O}_{2}$ measurements necessitate more rigorous testing, validation and benchmarking of the existing commercial instruments and new prototypes developed by researchers or companies. More comprehensive testing of sensor performance with different products and packaging processes and comparison of the different sensors systems with each other should be carried out more comprehensively. So far, very few such studies were conducted and published.

\section{Conclusions and Outlook}

The above sections illustrate the utility of photoluminescence based $\mathrm{O}_{2}$ sensing approach for non-destructive high-throughput monitoring of quality and safety of packaged foods, efficiency of active packaging materials, systems and particular food products. Disposable $\mathrm{O}_{2}$ sensors can provide robust response, fast and reliable measurement of dissolved and gaseous $\mathrm{O}_{2}$ level in a reversible, non-destructive, real-time manner and repetitively. They have been used with many different types of packaged foods and beverages, packaging materials and conditions. Existing $\mathrm{O}_{2}$ sensors have proven themselves as very useful and powerful tools for food quality and safety assurance, throughout the whole production, processing and distribution chain. They are actively used in food research and packaging, new product development and troubleshooting, in quality control tasks.

Food packaging with its huge market size (millions and billions of packs) has long been seen as the holy grail for $\mathrm{O}_{2}$ sensors, with potential to incorporate sensor in every commercial MAP pack. Unfortunately this has not materialised yet. Over the last decade, the $\mathrm{O}_{2}$ sensor technology has become mature, disposable calibration-free sensors are now produced commercially and their usage in food industry went up from dozens to hundreds (maybe thousands) per trial. However, this is far away from the anticipated scale (many millions). Sensors are still considered as useful research tools rather than necessity which can improve food safety and quality and attract new customers. 
The main challenges here are very low profit margins in the food industry (every cent is counted) and the diversity of packaged products, for many of which packaging materials and sensor materials should be individually tailored. This is augmented by a significant disconnect between the packaging companies, who are expected to incorporate $\mathrm{O}_{2}$ sensors in their packaging materials, and food processing companies who can use such 'smart' materials with their products. The former have to take the risk and invest heavily in sensor technology, while the latter - provide technical specifications, clear economic justification and solid commitment to use these smart materials on a large scale. The latter step implies a large (several orders of magnitude) spike in the number of sensors produced and used by the industry.

The high costs of existing sensors, relative complexity, general lack of flexibility and integration options make most of them unsuitable and unaffordable for large scale use in the food industry. Several critical issues need to be addressed. To be commercially viable, the disposable sensors should cost $<10$ cents (current cost $>\$ 1$ ), analytical performance, robustness and flexibility should further improve. The sensor materials should be made more compatible with the industrial packaging systems and facilitate integration of discrete $\mathrm{O}_{2}$ sensors in individual packs, which measurement instrumentation should become more convenient and less expensive. When developing new and improved $\mathrm{O}_{2}$ sensors, interactions between the sensor and food components, stability, cross-sensitivity, safety and ethical aspects should be assessed comprehensively. We anticipate that advanced sensor systems for packaging applications which embed these features will emerge in the near future.

\section{Acknowledgement}

Financial support of this work by the Irish Department of Agriculture, Food and Marine, grant DAFM/11/F/015, is gratefully acknowledged.

\section{References}

http://solutions.3m.com (Accessed on 07/07/2015)

http://www.mgc.co.jp/eng/products/abc/ageless/eye.html (Accessed on 07/07/2015)

Ahvenainen, R. (2003). Active and intelligent packaging: An introduction. In R. Ahvenainen (Ed.), Novel Food Packaging Techniques (pp. 5-21): Woodhead Publishing.

Ahvenainen, R., Eilamo, M., \& Hurme, E. (1997). Detection of improper sealing and quality deterioration of modified-atmosphere-packed pizza by a colour indicator. Food Control, 8, 177-184.

Alford, P. C., Cook, M. J., Lewis, A. P., McAuliffe, G. S. G., Skarda, V., Thomson, A. J., Glasper, J. L., \& Robbins, D. J. (1985). Luminescent metal complexes. Part 5. Luminescence properties of ring-substituted 1,10-phenanthroline tris-complexes of ruthenium(II). J. Chem. Soc., Perkin Trans. 2, 705-709.

Amanatidou, A., Smid, E. J., \& Gorris, L. G. M. (1999). Effect of elevated oxygen and carbon dioxide on the surface growth of vegetable-associated micro-organisms. $J$. Appl. Microbiol., 86, 429-438. 
Amao, Y. (2003). Probes and Polymers for Optical Sensing of Oxygen. Microchimica Acta, 143, 1-12.

Amao, Y., Asai, K., Miyashita, T., \& Okura, I. (1999). Novel optical oxygen sensing material: platinum porphyrin-styrene-pentafluorostyrene copolymer film. Anal. Commun., 36, 367-369.

Amao, Y., Miyashita, T., \& Okura, I. (2000). Optical oxygen detection based on luminescence change of metalloporphyrins immobilized in poly(isobutylmethacrylateco-trifluoroethylmethacrylate) film. Anal.Chim. Acta, 421, 167-174.

Amao, Y., Miyashita, T., \& Okura, I. (2001). Platinum tetrakis(pentafluorophenyl)porphyrin immobilized in polytrifluoroethylmethacrylate film as a photostable optical oxygen detection material. J. Fluorine Chem., 107, 101-106.

Amao, Y., \& Okura, I. (2009). Optical oxygen sensor devices using metalloporphyrins. $J$. Porphyrins and Phthalocyanines, 13, 1111-1122.

Amao, Y., Tabuchi, Y., Yamashita, Y., \& Kimura, K. (2002). Novel optical oxygen sensing material: metalloporphyrin dispersed in fluorinated poly(aryl ether ketone) films. Eur. Polym. J., 38, 675-681.

Avella, M., Errico, M., Gentile, G., \& Volpe, M. (2011). Nanocomposite Sensors for Food Packaging. In J. P. Reithmaier, P. Paunovic, W. Kulisch, C. Popov \& P. Petkov (Eds.), Nanotechnological Basis for Advanced Sensors (pp. 501-510): Springer Netherlands. (Chapter 53)

Badocco, D., Mondin, A., \& Pastore, P. (2012). Determination of thermodynamic parameters from light intensity signals obtained from oxygen optical sensors. Sens. Actuators, B, $163,165-170$.

Badocco, D., \& Pastore, P. (2008). Definition and Use of the Experimental Sensible Parameters To Characterize Sensitivity and Precision of a Generic Oxygen Optical Sensor. Anal. Chem., 80, 2091-2096.

Banerjee, S., Kuznetsova, R. T., \& Papkovsky, D. B. (2015). Solid-state oxygen sensors based on phosphorescent diiodo-borondipyrromethene dye. Sens. Actuators, B, 212, 229-234.

Basu, B. J. (2007). Optical oxygen sensing based on luminescence quenching of platinum porphyrin dyes doped in ormosil coatings. Sens. Actuators, B, 123, 568-577.

Borchert, N., Hempel, A., Walsh, H., Kerry, J. P., \& Papkovsky, D. B. (2012). High throughput quality and safety assessment of packaged green produce using two optical oxygen sensor based systems. Food Control, 28, 87-93.

Borchert, N. B., Kerry, J. P., \& Papkovsky, D. B. (2013). A $\mathrm{CO}_{2}$ sensor based on Ptporphyrin dye and FRET scheme for food packaging applications. Sens. Actuators, B, 176, 157-165.

Borisov, S., \& Klimant, I. (2009). Luminescent nanobeads for optical sensing and imaging of dissolved oxygen. Microchimica Acta, 164, 7-15.

Borisov, S., \& Klimant, I. (2012). New luminescent oxygen-sensing and temperature-sensing materials based on gadolinium(III) and europium(III) complexes embedded in an acridone-polystyrene conjugate. Anal. Bioanal. Chem., 404, 2797-2806.

Borisov, S. M., Fischer, R., Saf, R., \& Klimant, I. (2014). Exceptional Oxygen Sensing Properties of New Blue Light-Excitable Highly Luminescent Europium(III) and Gadolinium(III) Complexes. Adv. Funct. Mater., 24, 6548-6560.

Borisov, S. M., \& Klimant, I. (2007). Ultrabright Oxygen Optodes Based on Cyclometalated Iridium(III) Coumarin Complexes. Anal. Chem., 79, 7501-7509.

Borisov, S. M., Lehner, P., \& Klimant, I. (2011). Novel optical trace oxygen sensors based on platinum(II) and palladium(II) complexes with 5,10,15,20-meso-tetrakis-(2,3,4,5,6- 
pentafluorphenyl)-porphyrin covalently immobilized on silica-gel particles. Anal. Chim. Acta, 690, 108-115.

Borisov, S. M., Mayr, T., Mistlberger, G., Waich, K., Koren, K., Chojnacki, P., \& Klimant, I. (2009). Precipitation as a simple and versatile method for preparation of optical nanochemosensors. Talanta, 79, 1322-1330.

Borisov, S. M., Nuss, G., Haas, W., Saf, R., Schmuck, M., \& Klimant, I. (2009). New NIRemitting complexes of platinum(II) and palladium(II) with fluorinated benzoporphyrins. J. Photochem. Photobiol., A, 201, 128-135.

Borisov, S. M., Nuss, G., \& Klimant, I. (2008). Red Light-Excitable Oxygen Sensing Materials Based on Platinum(II) and Palladium(II) Benzoporphyrins. Anal. Chem., 80, 9435-9442.

Bradshaw, M. P., Barril, C., Clark, A. C., Prenzler, P. D., \& Scollary, G. R. (2011). Ascorbic Acid: A Review of its Chemistry and Reactivity in Relation to a Wine Environment. Crit. Rev. Food Sci. Nutr., 51, 479-498.

Carraway, E. R., Demas, J. N., DeGraff, B. A., \& Bacon, J. R. (1991). Photophysics and photochemistry of oxygen sensors based on luminescent transition-metal complexes. Anal. Chem., 63, 337-342.

Charlesworth, J. M. (1994). Optical sensing of oxygen using phosphorescence quenching. Sens. Actuators, B, 22, 1-5.

Chen, X., Zhong, Z., Li, Z., Jiang, Y., Wang, X., \& Wong, K. (2002). Characterization of ormosil film for dissolved oxygen-sensing. Sens. Actuators, B, 87, 233-238.

Chojnacki, P., Mistlberger, G., \& Klimant, I. (2007). Separable Magnetic Sensors for the Optical Determination of Oxygen. Angew. Chem., Int. Ed., 46, 8850-8853.

Chu, C.-S., \& Chuang, C.-Y. (2015). Optical fiber sensor for dual sensing of dissolved oxygen and $\mathrm{Cu}^{2+}$ ions based on PdTFPP/CdSe embedded in sol-gel matrix. Sens. Actuators, B, 209, 94-99.

Chu, C.-S., \& Lin, T.-H. (2014). A new portable optical sensor for dual sensing of temperature and oxygen. Sens. Actuators, B, 202, 508-515.

Chu, C.-S., \& Lo, Y.-L. (2011). Highly sensitive and linear calibration optical fiber oxygen sensor based on Pt(II) complex embedded in sol-gel matrix. Sens. Actuators, B, 155, 53-57.

Clark, L. C., Wolf, R., Granger, D., \& Taylor, Z. (1953). Continuous Recording of Blood Oxygen Tensions by Polarography. J. Appl. Physiol., 6, 189-193.

Cook, M. J., Lewis, A. P., McAuliffe, G. S. G., Skarda, V., Thomson, A. J., Glasper, J. L., \& Robbins, D. J. (1984). Luminescent metal complexes. Part 1. Tris-chelates of substituted 2,2-bipyridyls with ruthenium (II) as dyes for luminescent solar collectors. J. Chem. Soc., Perkin Trans. 2, 1293-1301.

http://dansensor.com/products/headspace-analysers (Accessed on 30/06/2015)

Demas, J. N., DeGraff, B. A., \& Xu, W. (1995). Modeling of Luminescence QuenchingBased Sensors: Comparison of Multisite and Nonlinear Gas Solubility Models. Anal. Chem., 67, 1377-1380.

DeRosa, M. C., Mosher, P. J., Yap, G. P. A., Focsaneanu, K. S., Crutchley, R. J., \& Evans, C. E. B. (2003). Synthesis, Characterization, and Evaluation of $\left[\operatorname{Ir}(\mathrm{ppy})_{2}(\mathrm{vpy}) \mathrm{Cl}\right]$ as a Polymer-Bound Oxygen Sensor. Inorg. Chem., 42, 4864-4872.

Diéval, J.-B., Vidal, S., \& Aagaard, O. (2011). Measurement of the Oxygen Transmission Rate of Co-extruded Wine Bottle Closures Using a Luminescence-Based Technique. Packaging Technology and Science, 24, 375-385.

Dmitriev, R. I., Borisov, S. M., Düssmann, H., Sun, S., Müller, B. J., Prehn, J., Baklaushev, V. P., Klimant, I., \& Papkovsky, D. B. (2015). Versatile Conjugated Polymer 
Nanoparticles for High-Resolution $\mathrm{O}_{2}$ Imaging in Cells and 3D Tissue Models. ACS Nano, 9, 5275-5288.

Douglas, P., \& Eaton, K. (2002). Response characteristics of thin film oxygen sensors, Pt and Pd octaethylporphyrins in polymer films. Sens. Actuators, B, 82, 200-208.

Draxler, S., Lippitsch, M. E., Klimant, I., Kraus, H., \& Wolfbeis, O. S. (1995). Effects of Polymer Matrixes on the Time-Resolved Luminescence of a Ruthenium Complex Quenched by Oxygen. J. Phys. Chem., 99, 3162-3167.

Eastwood, D., \& Gouterman, M. (1970). Porphyrins: XVIII. Luminescence of (Co), (Ni), Pd, Pt complexes. J. Mol. Spectrosc., 35, 359-375.

Eaton, K., \& Douglas, P. (2002). Effect of humidity on the response characteristics of luminescent PtOEP thin film optical oxygen sensors. Sens. Actuators, B, 82, 94-104.

Ermolina, E. G., Kuznetsova, R. T., Aksenova, Y. V., Gadirov, R. M., Kopylova, T. N., Antina, E. V., Berezin, M. B., \& Semeikin, A. S. (2014). Novel quenchometric oxygen sensing material based on diiodine-substituted boron dipyrromethene dye. Sens. Actuators, B, 197, 206-210.

Fischer, L. H., Karakus, C., Meier, R. J., Risch, N., Wolfbeis, O. S., Holder, E., \& Schäferling, M. (2012). Referenced Dual Pressure- and Temperature-Sensitive Paint for Digital Color Camera Read Out. Chem. - Eur. J., 18, 15706-15713.

Fitzgerald, M., Papkovsky, D., Smiddy, M., Kerry, J., O Sullivan, C., Buckley, D., \& Guilbault, G. (2001). Nondestructive monitoring of oxygen profiles in packaged foods using phase-fluorimetric oxygen sensor. J. Food. Sci., 66, 105-110.

Forster, L. S. (2002). Thermal relaxation in excited electronic states of $\mathrm{d}^{3}$ and $\mathrm{d}^{6}$ metal complexes. Coord. Chem. Rev., 227, 59-92.

http://www.fresh-check.com/ (Accessed on 07/07/2015)

Gibbs, E. L. (2013). Oxygen Permeation of BetterBottle ${ }^{\circledR}$ Carboys-Direct Measurement-.

Gillanders, R. N., Arzhakova, O. V., Hempel, A., Dolgova, A., Kerry, J. P., Yarysheva, L. M., Bakeev, N. F., Volynskii, A. L., \& Papkovsky, D. B. (2010). Phosphorescent Oxygen Sensors Based on Nanostructured Polyolefin Substrates. Anal. Chem., 82, 466-468.

Gillanders, R. N., Tedford, M. C., Crilly, P. J., \& Bailey, R. T. (2004). A composite solgel/fluoropolymer matrix for dissolved oxygen optical sensing. J. Photochem. Photobiol., A, 163, 193-199.

Han, J. H. (2003). Antimicrobial food packaging. In R. Ahvenainen (Ed.), Novel Food Packaging Techniques (pp. 50-70): Woodhead Publishing.

Hartmann, P., Leiner, M. J. P., \& Lippitsch, M. E. (1995). Luminescence Quenching Behavior of an Oxygen Sensor Based on a Ru(II) Complex Dissolved in Polystyrene. Anal. Chem., 67, 88-93.

Hempel, A., O'Sullivan, M. G., Papkovsky, D. B., \& Kerry, J. P. (2013). Use of optical oxygen sensors to monitor residual oxygen in pre- and post-pasteurised bottled beer and its effect on sensory attributes and product acceptability during simulated commercial storage. LWT-Food Sci. Technol., 50, 226-231.

Hempel, A., Sullivan, M., Papkovsky, D., \& Kerry, J. (2013). Assessment and Use of Optical Oxygen Sensors as Tools to Assist in Optimal Product Component Selection for the Development of Packs of Ready-to-Eat Mixed Salads and for the Non-Destructive Monitoring of in-Pack Oxygen Levels Using Chilled Storage. Foods, 2, 213.

Hempel, A. W., O’Sullivan, M. G., Papkovsky, D. B., \& Kerry, J. P. (2013). Use of smart packaging technologies for monitoring and extending the shelf-life quality of modified atmosphere packaged (MAP) bread: application of intelligent oxygen sensors and active ethanol emitters. Eur. Food Res. Technol., 237, 117-124. 
Hugi, A., \& Voirol, E. (2001). Instrumental measurements and sensory parameters. In E. Kress-Rogers \& C. J. B. Brimelow (Eds.), Instrumentation and Sensors for the Food Industry (Second Edition) (pp. 31-60): Woodhead Publishing.

Ishiji, T., Kudo, K., \& Kaneko. (1994). Microenvironmental studies of an Ru(bpy) ${ }_{3}{ }^{2+}$ luminescent probe incorporated into Nafion film and its application to an oxygen sensor. Sens. Actuators, B, 22, 205-210.

Jerónimo, P. C. A., Araújo, A. N., \& Conceição B.S.M. Montenegro, M. (2007). Optical sensors and biosensors based on sol-gel films. Talanta, 72, 13-27.

Kaniou, I., Samouris, G., Mouratidou, T., Eleftheriadou, A., \& Zantopoulos, N. (2001). Determination of biogenic amines in fresh unpacked and vacuum-packed beef during storage at $4^{\circ} \mathrm{C}$. Food Chemistry, 74, 515-519.

Kelly, C. A., Toncelli, C., Cruz-Romero, M., Arzhakova, O. V., Kerry, J. P., \& Papkovsky, D. B. (2015). Phosphorescent $\mathrm{O}_{2}$ sensors integrated in polymeric film materials by local solvent crazing. Mater. Des., 77, 110-113.

Kelly, C. A., Toncelli, C., Kerry, J. P., \& Papkovsky, D. B. (2014a). Discrete $\mathrm{O}_{2}$ sensors produced by a spotting method on polyolefin fabric substrates. Sens. Actuators, B, 203, 935-940.

Kelly, C. A., Toncelli, C., Kerry, J. P., \& Papkovsky, D. B. (2014b). Phosphorescent $\mathrm{O}_{2}$ sensors based on polyolefin fabric materials. J. Mater. Chem. C, 2, 2169-2174.

Kerry, J. P., O'Grady, M. N., \& Hogan, S. A. (2006). Past, current and potential utilisation of active and intelligent packaging systems for meat and muscle-based products: A review. Meat Sci., 74, 113-130.

Khalil, G., Gouterman, M., Ching, S., Costin, C., Coyle, L., Gouin, S., Green, E., Sadilek, M., Wan, R., Yearyean, J., \& Zelelow, B. (2002). Synthesis and spectroscopic characterization of $\mathrm{Ni}, \mathrm{Zn}, \mathrm{Pd}$ and $\mathrm{Pt}$ tetra(pentafluorophenyl)porpholactone with comparisons to $\mathrm{Mg}, \mathrm{Zn}, \mathrm{Y}, \mathrm{Pd}$ and $\mathrm{Pt}$ metal complexes of tetra(pentafluorophenyl)porphine. J. Porphyrins and Phthalocyanines, 06, 135-145.

Klimant, I., Kühl, M., Glud, R. N., \& Holst, G. (1997). Optical measurement of oxygen and temperature in microscale: strategies and biological applications. Sens. Actuators, B, 38, 29-37.

Klimant, I., Ruckruh, F., Liebsch, G., Stangelmayer, A., \& Wolfbeis, O. S. (1999). Fast Response Oxygen Micro-Optodes Based on Novel Soluble Ormosil Glasses. Microchimica Acta, 131, 35-46.

Klimant, I., \& Wolfbeis, O. S. (1995). Oxygen-Sensitive Luminescent Materials Based on Silicone-Soluble Ruthenium Diimine Complexes. Anal. Chem., 67, 3160-3166.

Kolle, C., Gruber, W., Trettnak, W., Biebernik, K., Dolezal, C., Reininger, F., \& O'Leary, P. (1997). Fast optochemical sensor for continuous monitoring of oxygen in breath-gas analysis. Sens. Actuators, B, 38, 141-149.

Kondrashina, A. V., Dmitriev, R. I., Borisov, S. M., Klimant, I., O'Brien, I., Nolan, Y. M., Zhdanov, A. V., \& Papkovsky, D. B. (2012). A Phosphorescent Nanoparticle-Based Probe for Sensing and Imaging of (Intra)Cellular Oxygen in Multiple Detection Modalities. Adv. Funct. Mater., 22, 4931-4939.

Koo Lee, Y.-E., Ulbrich, E. E., Kim, G., Hah, H., Strollo, C., Fan, W., Gurjar, R., Koo, S., \& Kopelman, R. (2010). Near Infrared Luminescent Oxygen Nanosensors with Nanoparticle Matrix Tailored Sensitivity. Anal. Chem., 82, 8446-8455.

Koren, K., Borisov, S. M., \& Klimant, I. (2012). Stable optical oxygen sensing materials based on click-coupling of fluorinated platinum(II) and palladium(II) porphyrins - A convenient way to eliminate dye migration and leaching. Sens. Actuators, B, 169, 173-181.

Korotcenkov, G. (2014) Handbook of Gas Sensor Materials. New York: Springer, USA. 
Korzeniowska, B., Raspe, M., Wencel, D., Woolley, R., Jalink, K., \& McDonagh, C. (2015). Development of organically modified silica nanoparticles for monitoring the intracellular level of oxygen using a frequency-domain FLIM platform. Rsc Adv., 5, 36938-36947.

Köse, M. E., Crutchley, R. J., DeRosa, M. C., Ananthakrishnan, N., Reynolds, J. R., \& Schanze, K. S. (2005). Morphology and Oxygen Sensor Response of Luminescent IrLabeled Poly(dimethylsiloxane)/Polystyrene Polymer Blend Films. Langmuir, 21, 8255-8262.

Kozak, W., \& Samotyja, U. (2013). The use of oxygen content determination method based on fluorescence quenching for rapeseed oil shelf-life assessment. Food Control, 33, 162-165.

Kress-Rogers, E. (2001). Instrumentation for food quality assurance. In E. Kress-Rogers \& C. J. B. Brimelow (Eds.), Instrumentation and Sensors for the Food Industry (Second Edition) (pp. 1-30): Woodhead Publishing.

Krumhar, K. C., \& Karel, M. 1992 Visual indicator system. US Patent 5096813.

Kumari, L., Narsaiah, K., Grewal, M. K., \& Anurag, R. K. (2015). Application of RFID in agri-food sector. Trends Food Sci. Technol., 43, 144-161.

Kuswandi, B., Wicaksono, Y., Jayus, Abdullah, A., Heng, L., \& Ahmad, M. (2011). Smart packaging: sensors for monitoring of food quality and safety. Sens. Instrum. Food Qual. Saf., 5, 137-146.

Lai, S.-W., Hou, Y.-J., Che, C.-M., Pang, H.-L., Wong, K.-Y., Chang, C. K., \& Zhu, N. (2004). Electronic Spectroscopy, Photophysical Properties, and Emission Quenching Studies of an Oxidatively Robust Perfluorinated Platinum Porphyrin. Inorg. Chem., $43,3724-3732$.

Lakowicz, J. R. (2006) Principles of Fluorescence Spectroscopy (Third Edition ed.): Springer, USA.

Lam, S. K., Chan, M. A., \& Lo, D. (2001). Characterization of phosphorescence oxygen sensor based on erythrosin B in sol-gel silica in wide pressure and temperature ranges. Sens. Actuators, B, 73, 135-141.

Law, G.-L., Pal, R., Palsson, L. O., Parker, D., \& Wong, K.-L. (2009). Responsive and reactive terbium complexes with an azaxanthone sensitiser and one naphthyl group: applications in ratiometric oxygen sensing in vitro and in regioselective cell killing. Chem. Commun., 7321-7323.

Lawrie, K., Mills, A., \& Hazafy, D. (2013). Simple inkjet-printed, UV-activated oxygen indicator. Sens. Actuators, B, 176, 1154-1159.

Lee, S.-K., \& Okura, I. (1997a). Optical Sensor for Oxygen Using a Porphyrin-doped Sol-Gel Glass. Analyst, 122, 81-84.

Lee, S.-K., \& Okura, I. (1997b). Photostable Optical Oxygen Sensing Material: Platinum Tetrakis(pentafluorophenyl)porphyrin Immobilized in Polystyrene. Anal. Commun., 34, 185-188.

Li, M., Zheng, B., Luo, D., Sun, H., Wang, N., Huang, Y., Dai, J., Xiao, D., Su, S.-J., \& Lu, Z. (2015). Small molecular neutral microcrystalline iridium(III) complexes as promising molecular oxygen sensors. Chem. Commun., 51, 1926-1929.

Lippitsch, M. E., Pusterhofer, J., Leiner, M. J. P., \& Wolfbeis, O. S. (1988). Fibre-optic oxygen sensor with the fluorescence decay time as the information carrier. Anal. Chim. Acta, 205, 1-6.

Loughran, M., \& Diamond, D. (2000). Monitoring of volatile bases in fish sample headspace using an acidochromic dye. Food Chemistry, 69, 97-103.

MacCraith, B. D., McDonagh, C. M., O'Keeffe, G., Keyes, E. T., Vos, J. G., O'Kelly, B., \& McGilp, J. F. (1993). Fibre optic oxygen sensor based on fluorescence quenching of 
evanescent-wave excited ruthenium complexes in sol-gel derived porous coatings. Analyst, 118, 385-388.

Malins, C., G. Glever, H., D. MacCraith, B., Fanni, S., \& G. Vos, J. (1999). The preparation of a sol-gel glass oxygen sensor incorporating a covalently bound fluorescent dye. Anal. Commun., 36, 3-4.

McDonagh, C., Kolle, C., McEvoy, A. K., Dowling, D. L., Cafolla, A. A., Cullen, S. J., \& MacCraith, B. D. (2001). Phase fluorometric dissolved oxygen sensor. Sens. Actuators, B, 74, 124-130.

McDonagh, C., MacCraith, B. D., \& McEvoy, A. K. (1998). Tailoring of SelGel Films for Optical Sensing of Oxygen in Gas and Aqueous Phase. Anal. Chem., 70, 45-50.

McEvoy, A. K., McDonagh, C., \& MacCraith, B. D. (1997). Optimisation of Sol-GelDerived Silica Films for Optical Oxygen Sensing. J. Sol-Gel Sci. Technol., 8, 11211125.

McRae, J. M., Day, M. P., Bindon, K. A., Kassara, S., Schmidt, S. A., Schulkin, A., Kolouchova, R., \& Smith, P. A. (2015). Effect of early oxygen exposure on red wine colour and tannins. Tetrahedron, 71, 3131-3137.

Medina-Rodriguez, S., Orriach-Fernandez, F. J., Poole, C., Kumar, P., de la Torre-Vega, A., Fernandez-Sanchez, J. F., Baranoff, E., \& Fernandez-Gutierrez, A. (2015). Copper(i) complexes as alternatives to iridium(iii) complexes for highly efficient oxygen sensing. Chem. Commun., 51, 11401-11404.

Meng, X., Kim, S., Puligundla, P., \& Ko, S. (2014). Carbon dioxide and oxygen gas sensorspossible application for monitoring quality, freshness, and safety of agricultural and food products with emphasis on importance of analytical signals and their transformation. J. Korean Soc. Appl. Biol. Chem., 57, 723-733.

Mestres, M., Busto, O., \& Guasch, J. (2000). Analysis of organic sulfur compounds in wine aroma. J. Chromatogr. A, 881, 569-581.

Mills, A. (2005). Oxygen indicators and intelligent inks for packaging food. Chem. Soc. Rev., 34, 1003-1011.

Mills, A., \& Graham, A. (2013). Extruded polymer films pigmented with a heterogeneous ion-pair based lumophore for $\mathrm{O}_{2}$ sensing. Analyst, 138, 6488-6493.

Mills, A., Graham, A., \& O'Rourke, C. (2014). A novel, titania sol-gel derived film for luminescence-based oxygen sensing. Sens. Actuators, B, 190, 907-912.

Mills, A., \& Thomas, M. (1997). Fluorescence-based Thin Plastic Film Ion-pair Sensors for Oxygen. Analyst, 122, 63-68.

http://www.mocon.com/instruments/ox-tran-model-2-21.html (Accessed on 25/06/2015)

Moenne, M. I., Saa, P., Laurie, V. F., Pérez-Correa, J. R., \& Agosin, E. (2014). Oxygen Incorporation and Dissolution During Industrial-Scale Red Wine Fermentations. Food Bioprocess Technol., 7, 2627-2636.

Mohebi, E., \& Marquez, L. (2015). Intelligent packaging in meat industry: An overview of existing solutions. J. Food Sci. Technol., 52, 3947-3964.

Moreno-Bondi, M. C., Wolfbeis, O. S., Leiner, M. J. P., \& Schaffar, B. P. H. (1990). Oxygen optrode for use in a fiber-optic glucose biosensor. Anal. Chem., 62, 2377-2380.

Morin, A., Xu, W., Demas, J. N., \& DeGraff, B. A. (2000). Oxygen Sensors Based on a Quenching of Tris-(4,7-diphenyl-1,10-phenanthroline)ruthenium(II) in Fluorinated Polymers. J. Fluoresc., 10, 7-12.

Morsy, M. K., Khalaf, H.H., Sharoba, A.M. and El-Tanahi, H.H. (April 2014). Applicability of Biosensor and Oxygen Sensor for Monitoring Spoilage and Bacterial Contaminants of Packed Minced Beef and Poultry. In 2nd International Conference On Biotechnology Applications In Agriculture (ICBAA). Benha University,Moshtohor and Hurghada, Egypt. 
Müller, B. J., Burger, T., Borisov, S. M., \& Klimant, I. (2015). High performance optical trace oxygen sensors based on NIR-emitting benzoporphyrins covalently coupled to silicone matrixes. Sens. Actuators, B, 216, 527-534.

Napp, J., Behnke, T., Fischer, L., Würth, C., Wottawa, M., Katschinski, D. M., Alves, F., Resch-Genger, U., \& Schäferling, M. (2011). Targeted Luminescent Near-Infrared Polymer-Nanoprobes for In Vivo Imaging of Tumor Hypoxia. Anal. Chem., 83, 90399046.

Nkhili, E., \& Brat, P. (2011). Reexamination of the ORAC assay: effect of metal ions. Anal. Bioanal. Chem., 400, 1451-1458.

O’Mahony, F. C., O’Riordan, T. C., Papkovskaia, N., Kerry, J. P., \& Papkovsky, D. B. (2006). Non-destructive assessment of oxygen levels in industrial modified atmosphere packaged cheddar cheese. Food Control, 17, 286-292.

Ogurtsov, V. I., \& Papkovsky, D. B. (1998). Selection of modulation frequency of excitation for luminescence lifetime-based oxygen sensors. Sens. Actuators, B, 51, 377-381.

http://www.oxysense.com/oxygen-measurement-accessories.html (Accessed on 08/07/2015)

http://www.oxysense.com/OxySense-brochures/permeation-system_OxyPerm.pdf (Accessed on $04 / 07 / 2017)$

Papkovsky, D. B. (1995). New oxygen sensors and their application to biosensing. Sens. Actuators, B, 29, 213-218.

Papkovsky, D. B., \& Dmitriev, R. I. (2013). Biological detection by optical oxygen sensing. Chem. Soc. Rev., 42, 8700-8732.

Papkovsky, D. B., O'Riordan, T. C., \& Guilbault, G. G. (1999). An Immunosensor Based on the Glucose Oxidase Label and Optical Oxygen Detection. Anal. Chem., 71, 15681573.

Papkovsky, D. B., Olah, J., Troyanovsky, I. V., Sadovsky, N. A., Rumyantseva, V. D., Mironov, A. F., Yaropolov, A. I., \& Savitsky, A. P. (1992). Phosphorescent polymer films for optical oxygen sensors. Biosens. Bioelectron., 7, 199-206.

Papkovsky, D. B., Ovchinnikov, A. N., Ogurtsov, V. I., Ponomarev, G. V., \& Korpela, T. (1998). Biosensors on the basis of luminescent oxygen sensor: the use of microporous light-scattering support materials. Sens. Actuators, B, 51, 137-145.

Papkovsky, D. B., Papkovskaia, N., Smyth, A., Kerry, J., \& Ogurtsov, V. I. (2000). Phosphorescent Sensor Approach for Non-Destructive Measurement of Oxygen in Packaged Foods: Optimisation of Disposable Oxygen Sensors and their Characterization Over a Wide Temperature Range. Anal. Lett., 33, 1755-1777.

Papkovsky, D. B., Ponomarev, G. V., Trettnak, W., \& O'Leary, P. (1995). Phosphorescent Complexes of Porphyrin Ketones: Optical Properties and Application to Oxygen Sensing. Anal. Chem., 67, 4112-4117.

Papkovsky, D. B., Smiddy, M. A., Papkovskaia, N. Y., \& Kerry, J. P. (2002). Nondestructive Measurement of Oxygen in Modified Atmosphere Packaged Hams Using a PhaseFluorimetric Sensor System. J. Food Sci., 67, 3164-3169.

Plastic Films in Food Packaging: Materials, Technology and Applications. (2012) S. Ebnesajjad. Elsevier.

Pospiskova, K., Safarik, I., Sebela, M., \& Kuncova, G. (2013). Magnetic particles-based biosensor for biogenic amines using an optical oxygen sensor as a transducer. Microchimica Acta, 180, 311-318.

Puklin, E., Carlson, B., Gouin, S., Costin, C., Green, E., Ponomarev, S., Tanji, H., \& Gouterman, M. (2000). Ideality of pressure-sensitive paint. I. Platinum tetra(pentafluorophenyl)porphine in fluoroacrylic polymer. J. Appl. Polym. Sci., 77, 2795-2804. 
Quaranta, M., Borisov, S., \& Klimant, I. (2012). Indicators for optical oxygen sensors. Bioanal. Rev., 4, 115-157.

Randell, K., Ahvenainen, R., Latva-Kala, K., Hurme, E., Mattila-Sandholm, T., \& HyvöNen, L. (1995). Modified Atmosphere-packed Marinated Chicken Breast and Rainbow Trout Quality as Affected by Package Leakage. J. Food Sci., 60, 667-672.

Rogers, J. E., Nguyen, K. A., Hufnagle, D. C., McLean, D. G., Su, W., Gossett, K. M., Burke, A. R., Vinogradov, S. A., Pachter, R., \& Fleitz, P. A. (2003). Observation and Interpretation of Annulated Porphyrins: Studies on the Photophysical Properties of meso-Tetraphenylmetalloporphyrins. J. Phys. Chem. A, 107, 11331-11339.

Rokka, M., Eerola, S., Smolander, M., Alakomi, H.-L., \& Ahvenainen, R. (2004). Monitoring of the quality of modified atmosphere packaged broiler chicken cuts stored in different temperature conditions: B. Biogenic amines as quality-indicating metabolites. Food Control, 15, 601-607.

Rooney, M. L. (1995). Active packaging in polymer films. In M. L. Rooney (Ed.), Active Food Packaging (pp. 74-110): Springer US. (Chapter 4)

Salmon, J.-M. (2006). Interactions between yeast, oxygen and polyphenols during alcoholic fermentations: Practical implications. LWT-Food Sci. Technol., 39, 959-965.

Schrenkhammer, P., \& Wolfbeis, O. S. (2008). Fully reversible optical biosensors for uric acid using oxygen transduction. Biosens. Bioelectron., 24, 994-999.

Shu, H.-C., Håkanson, H., \& Mattiasson, B. (1993). d-Lactic acid in pork as a freshness indicator monitored by immobilized d-lactate dehydrogenase using sequential injection analysis. Anal. Chim. Acta, 283, 727-737.

Smiddy, M., Fitzgerald, M., Kerry, J. P., Papkovsky, D. B., O' Sullivan, C. K., \& Guilbault, G. G. (2002). Use of oxygen sensors to non-destructively measure the oxygen content in modified atmosphere and vacuum packed beef: impact of oxygen content on lipid oxidation. Meat Sci., 61, 285-290.

Smolander, M. (2008). Freshness Indicators for Food Packaging. In Smart Packaging Technologies for Fast Moving Consumer Goods (pp. 111-127): John Wiley \& Sons, Ltd.

Smolander, M., Hurme, E., \& Ahvenainen, R. (1997). Leak indicators for modifiedatmosphere packages. Trends Food Sci. Technol., 8, 101-106.

Smolander, M., Hurme, E., Latva-Kala, K., Luoma, T., Alakomi, H.-L., \& Ahvenainen, R. (2002). Myoglobin-based indicators for the evaluation of freshness of unmarinated broiler cuts. Innovative Food Sci. Emerging Technol., 3, 279-288.

Songzhu, L., Xiangting, D., Jinxian, W., Guixia, L., Wenshen, Y., \& Ruokun, J. (2010). Fabrication of $\mathrm{Eu}(\mathrm{III})$ complex doped nanofibrous membranes and their oxygensensing properties. Spectrochim. Acta, Part A, 77, 885-889.

Stich, M. I. J., Fischer, L. H., \& Wolfbeis, O. S. (2010). Multiple fluorescent chemical sensing and imaging. Chem. Soc. Rev., 39, 3102-3114.

Stich, M. I. J., Schaeferling, M., \& Wolfbeis, O. S. (2009). Multicolor Fluorescent and Permeation-Selective Microbeads Enable Simultaneous Sensing of pH, Oxygen, and Temperature. Adv. Mater., 21, 2216-2220.

Suppakul, P., Miltz, J., Sonneveld, K., \& Bigger, S. W. (2003). Active Packaging Technologies with an Emphasis on Antimicrobial Packaging and its Applications. $J$. Food Sci., 68, 408-420.

Tang, Y., Tehan, E. C., Tao, Z., \& Bright, F. V. (2003). Solfel -Derived Sensor Materials That Yield Linear Calibration Plots, High Sensitivity, and Long-Term Stability. Anal. Chem., 75, 2407-2413.

Taoukis, P. S., \& Labuza, T. P. (1989). Applicability of Time-Temperature Indicators as Shelf Life Monitors of Food Products. J. Food Sci., 54, 783-788. 
Tian, Y., Shumway, B. R., \& Meldrum, D. R. (2010). A New Cross-Linkable Oxygen Sensor Covalently Bonded into Poly(2-hydroxyethyl methacrylate)-co-Polyacrylamide Thin Film for Dissolved Oxygen Sensing. Chem. Mater., 22, 2069-2078.

Toncelli, C., Arzhakova, O. V., Dolgova, A., Volynskii, A. L., Bakeev, N. F., Kerry, J. P., \& Papkovsky, D. B. (2014). Oxygen-Sensitive Phosphorescent Nanomaterials Produced from High-Density Polyethylene Films by Local Solvent-Crazing. Anal. Chem., 86, 1917-1923.

Toncelli, C., Arzhakova, O. V., Dolgova, A., Volynskii, A. L., Kerry, J. P., \& Papkovsky, D. B. (2014). Phosphorescent oxygen sensors produced by spot-crazing of polyphenylenesulfide films. J. Mater. Chem. C, 2, 8035-8041.

Trettnak, W., Gruber, W., Reininger, F., \& Klimant, I. (1995). Recent progress in optical oxygen sensor instrumentation. Sens. Actuators, B, 29, 219-225.

Ugliano, M., Dieval, J.-B., Siebert, T. E., Kwiatkowski, M., Aagaard, O., Vidal, S., \& Waters, E. J. (2012). Oxygen Consumption and Development of Volatile Sulfur Compounds during Bottle Aging of Two Shiraz Wines. Influence of Pre- and Postbottling Controlled Oxygen Exposure. J. Agric. Food Chem., 60, 8561-8570.

Ugliano, M., Kwiatkowski, M., Vidal, S., Capone, D., Siebert, T., Dieval, J.-B., Aagaard, O., \& Waters, E. J. (2011). Evolution of 3-Mercaptohexanol, Hydrogen Sulfide, and Methyl Mercaptan during Bottle Storage of Sauvignon blanc Wines. Effect of Glutathione, Copper, Oxygen Exposure, and Closure-Derived Oxygen. J. Agric. Food Chem., 59, 2564-2572.

V. O'Brien, C. C., M. Nygaard. (2009). Managing oxygen ingress at bottling. Wine Industry Journal, 24, 24-29.

Van Bree, I., Baetens, J. M., Samapundo, S., Devlieghere, F., Laleman, R., Vandekinderen, I., Noseda, B., Xhaferi, R., De Baets, B., \& De Meulenaer, B. (2012). Modelling the degradation kinetics of vitamin $\mathrm{C}$ in fruit juice in relation to the initial headspace oxygen concentration. Food Chem., 134, 207-214.

Van Bree, I., De Meulenaer, B., Samapundo, S., Vermeulen, A., Ragaert, P., Maes, K. C., De Baets, B., \& Devlieghere, F. (2010). Predicting the headspace oxygen level due to oxygen permeation across multilayer polymer packaging materials: A practical software simulation tool. Innovative Food Sci. Emerging Technol, 11, 511-519.

Van der Steen, C., Jacxsens, L., Devlieghere, F., \& Debevere, J. (2002). Combining high oxygen atmospheres with low oxygen modified atmosphere packaging to improve the keeping quality of strawberries and raspberries. Postharvest Biol. Technol., 26, 49-58.

Vinogradov, S., \& Wilson, D. (1997). Extended Porphyrins. In E. Nemoto, J. LaManna, C. Cooper, D. Delpy, K. Groebe, T. Hunt, P. Keipert, A. Mayevsky, R. Pittman, W. Rumsey, P. Vaupel \& D. Wilson (Eds.), Oxygen Transport to Tissue XVIII (Vol. 411, pp. 597-603): Springer US. (Chapter 74)

Vinogradov, S. A., \& Wilson, D. F. (1995). Metallotetrabenzoporphyrins. New phosphorescent probes for oxygen measurements. J. Chem. Soc., Perkin Trans. 2, 103-111.

http://vitsab.com/index.php/seafood-tti-labels/ (Accessed on 07/07/2015)

Wallington, N., Clark, A. C., Prenzler, P. D., Barril, C., \& Scollary, G. R. (2013). The decay of ascorbic acid in a model wine system at low oxygen concentration. Food Chem., 141, 3139-3146.

Wang, X.-d., Gorris, H. H., Stolwijk, J. A., Meier, R. J., Groegel, D. B. M., Wegener, J., \& Wolfbeis, O. S. (2011). Self-referenced RGB colour imaging of intracellular oxygen. Chem. Sci., 2, 901-906.

Wang, X.-d., \& Wolfbeis, O. S. (2014). Optical methods for sensing and imaging oxygen: materials, spectroscopies and applications. Chem. Soc. Rev., 43, 3666-3761. 
Wang, Z., McWilliams, A. R., Evans, C. E. B., Lu, X., Chung, S., Winnik, M. A., \& Manners, I. (2002). Covalent Attachment of RuII Phenanthroline Complexes to Polythionylphosphazenes: The Development and Evaluation of Single-Component Polymeric Oxygen Sensors. Adv. Funct. Mater., 12, 415-419.

Wibowo, S., Grauwet, T., Santiago, J. S., Tomic, J., Vervoort, L., Hendrickx, M., \& Van Loey, A. (2015). Quality changes of pasteurised orange juice during storage: A kinetic study of specific parameters and their relation to colour instability. Food Chem., 187, 140-151.

Wirth, J., Caillé, S., Souquet, J. M., Samson, A., Dieval, J. B., Vidal, S., Fulcrand, H., \& Cheynier, V. (2012). Impact of post-bottling oxygen exposure on the sensory characteristics and phenolic composition of Grenache rosé wines. Food Chem., 132, 1861-1871.

Wolfbeis, O., Leiner, M. P., \& Posch, H. (1986). A new sensing material for optical oxygen measurement, with the indicator embedded in an aqueous phase. Microchimica Acta, 90, 359-366.

Xavier, M. P., García-Fresnadillo, D., Moreno-Bondi, M. C., \& Orellana, G. (1998). Oxygen Sensing in Nonaqueous Media Using Porous Glass with Covalently Bound Luminescent Ru(II) Complexes. Anal. Chem., 70, 5184-5189.

Xu, H., Aylott, J. W., Kopelman, R., Miller, T. J., \& Philbert, M. A. (2001). A Real-Time Ratiometric Method for the Determination of Molecular Oxygen Inside Living Cells Using SolGel-Based Spherical Optical Nanosensors with Applications to Rat C6 Glioma. Anal. Chem., 73, 4124-4133.

Xu, W., McDonough, R. C., Langsdorf, B., Demas, J. N., \& DeGraff, B. A. (1994). Oxygen Sensors Based on Luminescence Quenching: Interactions of Metal Complexes with the Polymer Supports. Anal. Chem., 66, 4133-4141.

Xue, R., Ge, C., Richardson, K., Palmer, A., Viapiano, M., \& Lannutti, J. J. (2015). Microscale Sensing of Oxygen via Encapsulated Porphyrin Nanofibers: Effect of Indicator and Polymer "Core" Permeability. ACS Appl. Mater. Interfaces, 7, 86068614.

Yam, K. L., Takhistov, P. T., \& Miltz, J. (2005). Intelligent Packaging: Concepts and Applications. J. Food Sci., 70, R1-R10.

Yam, K. L., Yam, K. L., \& Davis, M. W. (2010) The Wiley Encyclopedia of Packaging Technology (pp. 547-565): John Wiley \& Sons, Inc. 